\title{
Distinct Mechanisms Underlie Quiescence during Two Caenorhabditis elegans Sleep-Like States
}

\author{
(Nicholas F. Trojanowski, ${ }^{1,2,3}{ }^{\circledR}$ Matthew D. Nelson, ${ }^{1}$ Steven W. Flavell, ${ }^{4}$ Christopher Fang-Yen, ${ }^{2,3}$ and David M. Raizen ${ }^{1}$ \\ ${ }^{1}$ Department of Neurology and ${ }^{2}$ Department of Neuroscience, Perelman School of Medicine, University of Pennsylvania, ${ }^{3}$ Department of Bioengineering, \\ School of Engineering and Applied Science, University of Pennsylvania, Philadelphia, Pennsylvania 19104, and ${ }^{4}$ Howard Hughes Medical Institute, Lulu and \\ Anthony Wang Laboratory of Neural Circuits and Behavior, The Rockefeller University, New York, New York 10065
}

Electrophysiological recordings have enabled identification of physiologically distinct yet behaviorally similar states of mammalian sleep. In contrast, sleep in nonmammals has generally been identified behaviorally and therefore regarded as a physiologically uniform state characterized by quiescence of feeding and locomotion, reduced responsiveness, and rapid reversibility. The nematode Caenorhabditis elegans displays sleep-like quiescent behavior under two conditions: developmentally timed quiescence (DTQ) occurs during larval transitions, and stress-induced quiescence (SIQ) occurs in response to exposure to cellular stressors. Behaviorally, DTQ and SIQ appear identical. Here, we use optogenetic manipulations of neuronal and muscular activity, pharmacology, and genetic perturbations to uncover circuit and molecular mechanisms of DTQ and SIQ. We find that locomotion quiescence induced by DTQ- and SIQ-associated neuropeptides occurs via their action on the nervous system, although their neuronal target(s) and/or molecular mechanisms likely differ. Feeding quiescence during DTQ results from a loss of pharyngeal muscle excitability, whereas feeding quiescence during SIQ results from a loss of excitability in the nervous system. Together these results indicate that, as in mammals, quiescence is subserved by different mechanisms during distinct sleep-like states in C. elegans.

Key words: C. elegans; invertebrate; neural circuit; optogenetics; sleep

Significance Statement

Sleep behavior is characterized by cessation of feeding and locomotion, reduced responsiveness, and rapid reversibility. In mammals and birds, there are sleep states that have fundamentally different electrophysiology despite outwardly similar behavior. However, it is not clear whether behavioral sleep is a uniform state in animals in which electrophysiology is not readily possible. The nematode Caenorhabditis elegans displays sleep-like behavior under two conditions: during development and after exposure to environmental stressors. Here, we show that feeding and locomotion quiescence during these two sleep-like states are produced by different mechanisms. This provides the first identification of two mechanistically distinct forms of quiescence during sleep-like states in an invertebrate.

\section{Introduction}

Over the past 15 years, the study of small, nonmammalian genetic models such as zebrafish, fruit flies, and roundworms has yielded

Received April 9, 2015; revised Sept. 15, 2015; accepted Sept. 22, 2015.

Author contributions: N.F.T., C.F.-Y., and D.M.R. designed research; N.F.T. performed research; M.D.N. and S.W.F. contributed unpublished reagents/analytic tools; N.F.T., C.F.-Y., and D.M.R. analyzed data; N.F.T., M.D.N., S.W.F., C.F.-Y., and D.M.R. wrote the paper.

Some strains were provided by the Caenorhabditis Genetics Center, which is funded by the National Institutes of Health (NIH) Office of Research Infrastructure Programs (Grant P40 0D010440). N.F.T. was supported by the NIH (Grant T32-HL-07953). S.W.F. was supported by the Howard Hughes Medical Institute. C.F.-Y. was supported by an Alfred P. Sloan Research Fellowship and by the NIH (Grants R01-NS-084835, R01-NS-088432, and R21-NS-091500). D.M.R. was supported by the NIH (Grants R01-NS-064030, R01-NS-088432, and R21-NS-091500).

M.D. Nelson's present address: Department of Biology, Saint Joseph's University, Philadelphia, Pennsylvania 19131.

Correspondence should be addressed to either of the following: Christopher Fang-Yen, Department of Bioengineering, 210 S. 33rd Street, 240 Skirkanich Hall, University of Pennsylvania, Philadelphia, PA 19104, E-mail: many insights into the mechanisms of sleep regulation (Crocker and Sehgal, 2010). Electrophysiological characterization of sleep states, which is routinely used to identify sleep and its substages in mammals, is difficult in these smaller organisms, so sleep in nonmammals has typically been defined as a behavioral state characterized by quiescence of feeding and locomotion with an elevated arousal threshold and rapid reversibility (Allada and Siegel, 2008; Zimmerman et al., 2008). However, electroencephalography (EEG) has revealed that, despite its apparent behavioral homogeneity, mammalian sleep is not a physiologically homogenous state (Loomis et al., 1937). For example, despite appearing be-

fangyen@seas.upenn.edu; or David M. Raizen, Department of Neurology, 210 S. 33rd Street, 240 Skirkanich Hall, University of Pennsylvania, Philadelphia, PA 19104, E-mail: raizen@mail.med.upenn.edu. DOI:10.1523/JNEUROSCI.1369-15.2015

Copyright $\odot 2015$ the authors $\quad 0270-6474 / 15 / 3514571-14 \$ 15.00 / 0$ 
A

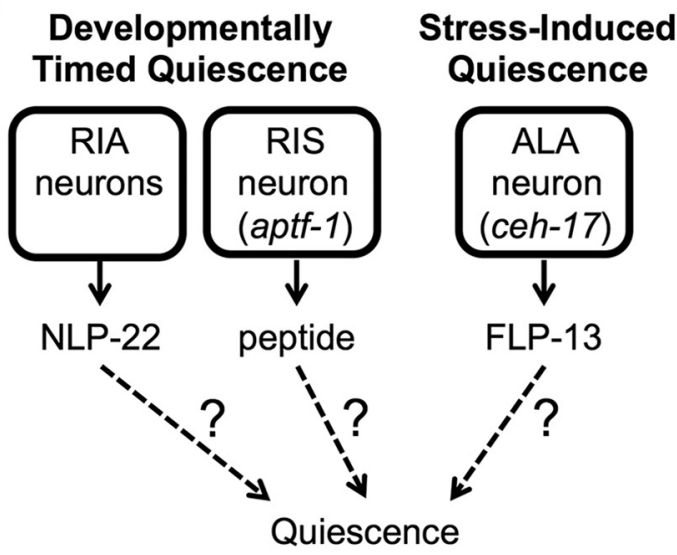

B

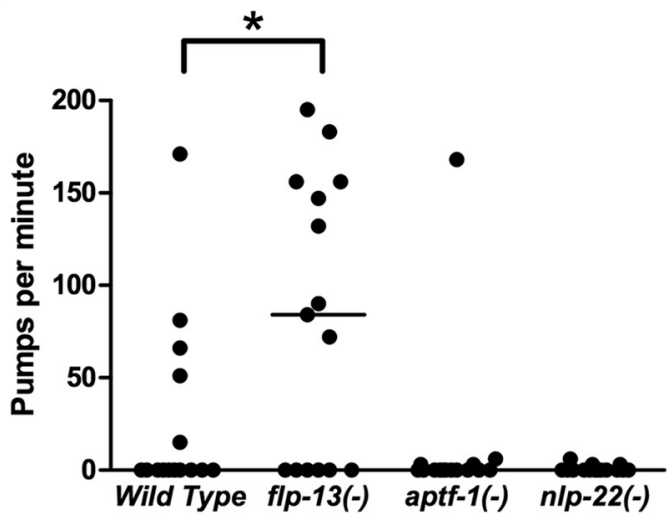

Figure 1. Quiescence during DTQ and SIQ is mediated by different neuropeptides. $A$, Schematic representing the known pathways that control quiescence during DTQ and SIQ. In DTQ, the RIA neurons release NLP-22, whereas the RIS neuron releases an unidentified peptide. The aptf-1 gene is required for the function of the RIS neuron and the ceh-17 gene is required for the function of the ALA neuron. During SIQ, the ALA neuron releases the FLP-13 neuropeptides. It is unknown how these neuropeptides lead to behavioral quiescence. $B$, Feeding quiescence during SIQ does not require pathways that regulate DTQ. Mutants defective in RIA and RIS signaling (nIp-22 and aptf- 1 mutants, respectively) have normal feeding quiescence during SIQ. Each point represents an observation from one worm and the horizontal bar represents the median of each group. $n=15$ for each group. Statistical significance was calculated using the Mann-Whitney test. ${ }^{*} p<0.05$.

haviorally essentially identical, REM and non-REM sleep are regulated by drastically different circuit and neurochemical mechanisms (Siegel, 2005).

The presence of distinct states of mammalian sleep raises the important question of whether behaviorally indistinguishable sleep states can be physiologically distinct in animals for which EEG is not feasible. In the nematode Caenorhabditis elegans, two behaviorally indistinguishable sleep-like states have been observed. Developmentally timed quiescence (DTQ), or lethargus, occurs during larval transitions (Raizen et al., 2008), and is coupled to a larval timing mechanism involving LIN-42, a homolog of the circadian timing protein PERIOD (Jeon et al., 1999; Monsalve et al., 2011). Stress-induced quiescence (SIQ) follows exposure to conditions that induce cellular stress and requires the epidermal growth factor (EGF) LIN-3 (Hill et al., 2014). Both states are characterized by a cessation of locomotion and feeding and reduced responsiveness to weak sensory stimuli, and animals in DTQ as well as those in SIQ resume movement but not feeding in response to a strong mechanical stimulation (Cassada and Russell, 1975; Jones and Candido, 1999; Raizen et al., 2008; Hill et al., 2014). Sensory neuron $\mathrm{Ca}^{2+}$ levels are decreased both during DTQ and after overexpression of EGF (mimicking SIQ), demonstrating that the physiology immediately proximal to increased arousal threshold is similar between these states (Cho and Sternberg, 2014). The molecular genetic regulation of DTQ (Choi et al., 2013; Nelson and Raizen, 2013; Schwarz and Bringmann, 2013; Singh et al., 2014) has several similarities to the regulation of circadian-timed sleep in Drosophila (Renn et al., 1999; Hendricks et al., 2001; Joiner et al., 2006; Parisky et al., 2008; Guo et al., 2011; He et al., 2013), whereas the molecular genetic regulation of SIQ (Nelson et al., 2014) has similarities to the regulation of stress-induced sleep in Drosophila (Zimmerman et al., 2008; Lenz et al., 2015), demonstrating conserved mechanisms of quiescence regulation between $C$. elegans and other animals.

Recent evidence suggests that there might be differences in the underlying molecular and circuit mechanisms that regulate behavioral quiescence during DTQ and SIQ. For example, disruption of the function of the ALA interneuron results in severely defective quiescence after cellular stress (Hill et al., 2014), but only minor changes in quiescence during larval development (Van Buskirk and Sternberg, 2007), and key neurotransmitters used by the ALA interneuron to induce quiescence, the seven FMRFamide-like neuropeptides encoded by the $f l p-13$ gene, are required for normal quiescence during SIQ but not DTQ (Nelson et al., 2014).

In this study, we aimed to elucidate differences and similarities in the circuit and molecular mechanisms underlying behavioral quiescence during DTQ and SIQ. Our results suggest that, despite the outwardly identical appearance of DTQ and SIQ, feeding and locomotion inhibition arise from fundamentally distinct circuit and molecular mechanisms during these states.

\section{Materials and Methods}

Worm strains and cultivation. We performed all experiments with hermaphrodites. Unless otherwise specified, animals were cultivated on the surface of NGM agar in a $20^{\circ} \mathrm{C}$ incubator. To conditionally overexpress $n l p-22$ and $f l p-13$, we used the strains NQ251 qnIs142[Phsp-16.2::nlp-22; Phsp-16.2::GFP; Pmyo-2::mCherry; unc-119(+)] (Nelson et al., 2013) and NQ570 qnIs303[Phsp-16.2::flp-13; Phsp-16.2::GFP; Prab-3::mCherry] (Nelson et al., 2014), respectively. The mutant strains that we used in our candidate screen are KG421 gsa-1(ce81gf) I (Schade et al., 2005), KG518 acy-1 (ce2gf) III (Schade et al., 2005), KG744 pde-4(ce268) II (Charlie et al., 2006), KG532 kin-2(ce179) X (Schade et al., 2005), JT734 goa-1(sa734) I (Robatzek and Thomas, 2000), PS998 goa-1 (sy192dn) I (Mendel et al., 1995), CG21 egl-30(tg26gf) I (Doi and Iwasaki, 2002), JT609 eat-16(sa609) I (Hajdu-Cronin et al., 1999), KP1097 dgk-1(nu62) X (Nurrish et al., 1999), NL594 gpa-12(pk322) X (Jansen et al., 1999), MJ500 tpa-1 (k501) IV (Tabuse and Miwa, 1983), DA467 eat-6(ad467) V (Avery, 1993), MT6129 egl19(n2368ff) IV (Lee et al., 1997), VC223 tom-1 (ok285) I (Dybbs et al., 2005), NM1968 slo-1(js379) $V$ (Wang et al., 2001), DR1089 unc-77(e625gf) IV (Brenner, 1974), MC339 unc-64(md130) III (Saifee et al., 1998), CB5 unc7(e5) X (Brenner, 1974), MT9455 tbh-1 (n3247) X (Alkema et al., 2005), and MT1074 egl-4(n479) IV (Trent et al., 1983). Other strains we used include N2 (Brenner, 1974), VC1669 aptf-1 (gk794) II (Turek et al., 2013), NQ596 nlp22(gk509904) X (Nelson et al., 2013), NQ602 flp-13(tm2427) IV (Nelson et al., 2014), NQ670 qnEx95[Phsp16.2::nlp-22; Pmyo-2::mCherry; unc-119(+)] (Nelson et al., 2013), NQ230 ceh-17(np1) I; qnEx95 [Phsp16.2::nlp-22; Pmyo-2::mCherry; unc-119(+)] (Nelson et al., 2013), NQ777 ceh-17(np1) I; qnIs303[Phsp-16.2::flp-13; Phsp-16.2::GFP; Prab-3::mCherry] (Nelson et al., 2014), ZM3265 lin-15(n765ts) X; zxIs6[Punc-17::ChR2(H134R)::YFP; lin-15(+)] V (Liewald et al., 2008), YX11 vsIs48[Punc-17::GFP] X; zxIs6[Punc-17::ChR2(H134R)::YFP; lin15(+)] V (Trojanowski et al., 2014), YX62 qnIs142[Phsp-16.2::nlp-22; Phsp-16.2::GFP; Pmyo-2::mCherry; unc-119(+)]; vsIs48[Punc-17::GFP] X; zxIs6[Punc-17::ChR2(H134R)::YFP; lin-15(+)] V, YX63 qnIs303[Phsp- 


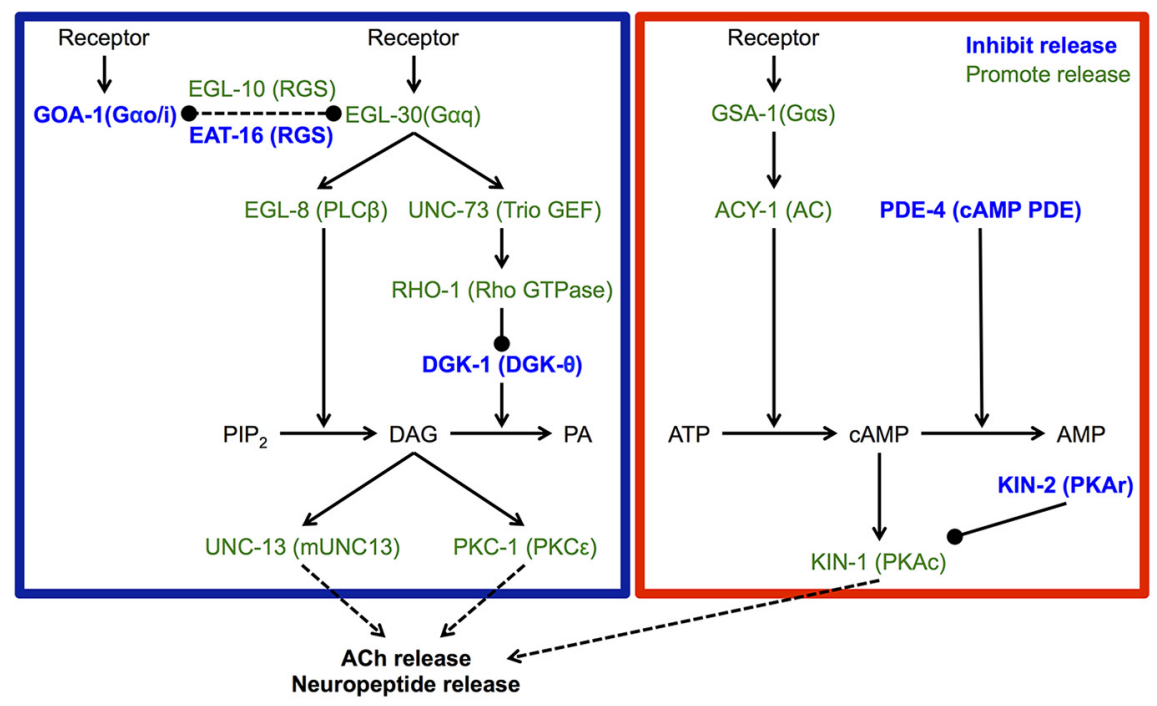

Figure 2. Schematic representation of the $G \alpha q$ and $G \alpha$ s pathways that regulate neurotransmitter secretion in C. elegans. $G \alpha q$ signaling causes increased DAG levels, whereas the G $\alpha$ s pathway causes increased cAMP levels. C. elegans protein names are shown in uppercase letters and mammalian homolog names are shown in parentheses. The blue box surrounds the $G \alpha q$ pathway and the red box surrounds the $G \alpha$ s pathway. Proteins labeled in blue inhibit neurotransmitter release and those in green promote release. Lines ending in arrows are positive regulation; lines ending in balls are negative regulation. Figure modeled after PerezMansilla and Nurrish (2009).

16.2::flp-13; Phsp-16.2::GFP; Prab-3::mCherry]/+; vsIs48[Punc-17::GFP] X; zxIs6[Punc-17::ChR2(H134R)::YFP; lin-15(+)] V, SJU8 kin-2(ce179); qnEx448[Punc-17::kin-2(+); Pmyo-3::mCherry], NQ902 kin-2(ce179) X; qnIs303[Phsp-16.2::flp-13; Phsp-16.2::GFP; Prab-3::mCherry]; qnEx448 [Punc-17::kin-2(+); Pmyo-3::mCherry], NQ903 kin-2(ce179) X; qnIs142 [Phsp-16.2::nlp-22; Phsp-16.2::GFP; Pmyo-2:::mCherry; unc-119(+)]; qnEx 448[Punc-17::kin-2(+); Pmyo-3::mCherry], NQ820 qnEx390[Pmyo-2:: GCaMP6s::SL2:::dsRed; rol-6(d)], CX16557 kyIs5640[Pmyo-2::Chrimson; Pelt-2::his-4.4-mCherry], and NQ904 qnEx390[Pmyo-2::GCaMP6s::SL2:: dsRed; rol-6(d)]; kyIs5640[Pmyo-2::Chrimson; Pelt-2::his-4.4-mCherry].

Acute heat shock. Unless otherwise indicated, we triggered stressinduced quiescence by acute heat shock, performed as described in "protocol 1" by Nelson et al. (2014). We heat-shocked day one adults at $35^{\circ} \mathrm{C}$ in a water bath for $30 \mathrm{~min}$ on standard NGM agar plates seeded with DA837. We then counted pumping rate as described previously (Raizen et al., 2012) for individual worms between 35 and $45 \mathrm{~min}$ after the end of heat shock.

Conditional neuropeptide overexpression. Unless otherwise indicated, to induce neuropeptide overexpression we placed day one adults on NGM agar plates seeded with DA837 in a $33^{\circ} \mathrm{C}$ water bath for $30 \mathrm{~min}$ and allowed them to recover at room temperature for $2-3 \mathrm{~h}$, at which time the effects of acute heat shock had worn off (Nelson et al., 2013, 2014). To screen for mutants with abnormal $f l p-13$ - or $n l p$-22-induced quiescence, we tested all of the candidate strains overexpressing one neuropeptide gene on the same day with the experimenter blinded to the genotype of the strains. We counted the number of pumps per $20 \mathrm{~s}$ and the number of body bends per $20 \mathrm{~s}$ (where one full back and forth movement of the anterior body was counted as one body bend) for each of 12-15 worms. We tripled each value to convert to pumps per minute or body bends per minute. For experiments testing the effect of $c e h-17$ mutation on $n l p-22$ and $f l p-13$ overexpression-induced quiescence, we used NQ670 and NQ570 as the respective control strains.

Effects of 5-HT. To test the effect of 5-HT on feeding after neuropeptide overexpression, during SIQ, or during DTQ, we immobilized worms on agarose pads containing $10 \mathrm{~mm} 5-\mathrm{HT}$ as described previously (Trojanowski et al., 2014).

Single neuron optogenetics. We performed optogenetic stimulation of single neurons after neuropeptide overexpression as described previously (Trojanowski et al., 2014, Trojanowski and Fang-Yen, 2015) except that the worms were first submitted to the conditional neuropeptide overexpression protocol, as described above. We examined worms between 2 and $3 \mathrm{~h}$ after heat shock.

Wide-field optogenetics. To stimulate pharyngeal neurons during SIQ or DTQ, we grew ZM3265 worms on OP50 containing all-trans retinal (ATR) as described previously (Trojanowski et al., 2014). For SIQ, we performed acute heat shock as described above except that plates seeded with ATR-containing OP50 were used. We then illuminated these worms with blue light (using GFP optics, irradiance $=0.66$ $\mathrm{mW} / \mathrm{mm}^{2}$ ) from a mercury halide lamp on a Leica MZ16F stereomicroscope and quantified pump rate in $20 \mathrm{~s}$ intervals (Raizen et al., 2012). We tripled these values to calculate pumps per minute.

Pharyngeal muscle optogenetics. We performed optogenetic stimulation of pharyngeal muscle during wake and DTQ similarly to stimulation of single neurons, with some modifications because Chrimson was not tagged with a fluorescent protein. First, we stimulated the entire head region of the worm instead of only the pharynx by setting the digital micro mirror device to illuminate the entire field of view. Next, we used a pulse generator (Stanford Research Systems DG535) to generate $5 \mathrm{~V}$ pulses of a specified duration and frequency and connected this output to the modulation input of the laser to control stimulus timing. To identify the stimulus interval on the camera, we attached a red collimated LED to the same pulse generator output via a relay and directed this light toward the objective, allowing us to detect a small increase in bright-field intensity when the laser was on. All other aspects of the experiment were unchanged.

$\mathrm{Ca}^{2+}$ imaging. We performed experiments using GCaMP6s the same way as pharyngeal muscle optogenetics experiments with slight modifications. With the laser continuously illuminating the field of view, we recorded the Pmyo-2::GCaMP6s signal for about 30 s (1000 frames at 30 frames/s). We then identified the maximum and minimum fluorescence values in a region of the metacorpus during this time and calculated the difference between these values to determine the maximum fluorescence change during this interval. The laser power we used here was the same as that for optogenetics experiments.

Strain construction. To rescue the kin-2 defect specifically in cholinergic neurons, we used an Eppendorf FemtoJet microinjection system on a Leica DMIRB inverted differential interference contrast microscope to inject Punc-17::kin-2::unc-54utr in CFJ151 at $25 \mathrm{ng} / \mu \mathrm{l}$ in combination with $5 \mathrm{ng} / \mu \mathrm{l}$ pCFJ104(Pmyo-3::mCherry). We created the Punc-17::kin-2::unc-54utr construct using standard Gateway cloning procedures. Briefly, we recombined Punc-17 in pDONR P4P1r and kin-2 cDNA in pDONR221 into the CFJ151 destination vector. To create qn390, we used overlap extension PCR (Nelson and Fitch, 2011) to generate Pmyo-2::GCaMP6s::SL2::dsRed. We then injected Pmyo-2::GCaMP6s::SL2:: dsRed at $20 \mathrm{ng} / \mu \mathrm{l}$ and $p R F 4$ at $100 \mathrm{ng} / \mu \mathrm{l}$ into N2. We created Pmyo-2::Chrimson by subcloning the myo-2 promoter into the pSM-Chrimson vector (Gordus et al., 2015) using FseI and AscI. To generate kyIs5640, we injected Pmyo-2::Chrimson at $0.4 \mathrm{ng} / \mu \mathrm{l}$ in combination with $5 \mathrm{ng} / \mu \mathrm{l}$ Pelt-2::his-4.4-mCherry. The resulting extrachromosomal array spontaneously integrated during the course of strain maintenance (Mello et al., 1991).

To construct the strains used to test gene mutation effects on the behavioral quiescence conferred by neuropeptide overexpression, we followed the red fluorescent reporter on the transgene array (Pmyo-2::mCherry or Prab-3::mCherry) and the visible phenotypes of the gene mutation. In cases in which the phenotype of the gene mutation was difficult to identify, we made use of balanced chromosomes marked with GFP fluorescence (Edgley et al., 2006). 
Table 1. Candidate mutants for suppression of FLP-13 and NLP-22 overexpression studied in Figures 3 and 4, their vertebrate homologs, and the reasons that these mutants were selected for study

\begin{tabular}{|c|c|c|c|c|}
\hline Gene mutated & Change in function & Vertebrate homolog & Reason chosen & Reference \\
\hline gsa-1 & Gain & $\mathrm{G} \alpha \mathrm{s}$ & Reduced lethargus quiescence; resistant to isoflurane & (Saifee et al., 2011; Schwarz and Bringmann, 2013) \\
\hline$a c y-1$ & Gain & Adenylate cyclase & Reduced lethargus quiescence & (Iwanir et al., 2013) \\
\hline pde-4 & Loss & PDE4 & Reduced lethargus quiescence & (Singh et al., 2014) \\
\hline kin-2 & Loss & PKA regulatory subunit & Reduced lethargus quiescence; resistant to isoflurane & (Saifee et al., 2011; Belfer et al., 2013) \\
\hline goa-1 & DN & $\mathrm{G} \alpha \mathrm{i} / 0$ & Reduced lethargus quiescence & (Singh et al., 2014) \\
\hline$g 0 a-1$ & Loss & $\mathrm{G} \alpha \mathrm{i} / 0$ & Resistant to halothane & (van Swinderen et al., 2001) \\
\hline egl-30 & Gain & $\mathrm{G} \alpha q$ & Reduced lethargus quiescence; resistant to halothane & (Hawasli et al., 2004; Schwarz and Bringmann, 2013) \\
\hline eat-16 & Loss & G $\alpha q$ RGS & Resistant to halothane and isoflurane & (van Swinderen et al., 2001) \\
\hline$d g k-1$ & Loss & DGK- $\theta$ & Resistant to halothane & (van Swinderen et al., 2002) \\
\hline gpa-12 & Loss & $\mathrm{G} \alpha 12$ & Activation inhibits feeding & (van der Linden et al., 2003) \\
\hline tpa-1 & Loss & $\operatorname{PKC} \delta$ & Suppresses effects of gpa-12 activation & (van der Linden et al., 2003) \\
\hline eat-6 & Loss & $\mathrm{Na}^{+} / \mathrm{K}^{+}$ATPase & Depolarized pharyngeal muscle & (Davis et al., 1995) \\
\hline egl-19 & Gain & L-type $\mathrm{Ca}^{2+}$ channel & Prolonged pharyngeal action potential & (Lee et al., 1997) \\
\hline tom-1 & Loss & Tomosyn & Increased neurotransmission & (Dybbs et al., 2005) \\
\hline slo-1 & Loss & BK channel & Increased neurotransmission; resistant to halothane & (Wang et al., 2001; Hawasli et al., 2004) \\
\hline unc-77 & Gain & NALCN channel & Resistant to halothane & (Humphrey et al., 2007) \\
\hline unc-64 & Neomorph & Syntaxin & Resistant to halothane and isoflurane & (van Swinderen et al., 1999) \\
\hline unc-7 & Loss & Innexin & Resistant to halothane & (Morgan et al., 1990) \\
\hline tbh-1 & Loss & Tyramine $\beta$-hydroxylase & Opposes 5-HT response & (Wragg et al., 2007) \\
\hline egl-4 & Loss & PKG & Reduced lethargus quiescence & (Raizen et al., 2008) \\
\hline
\end{tabular}

DN, Dominant-negative.

Statistics. For the candidate mutant screens, we used Dunnett's multiple-comparison tests to determine which mutants were significantly different from the control. For the single neuron optogenetics, we performed a one-way ANOVA to determine whether there was an effect of neuron stimulation on pumping rate. For stress-induced quiescence experiments, we used a Mann-Whitney test without post hoc correction to determine which mutants were significantly different from the control. See figure legends for details.

\section{Results}

\section{Feeding quiescence during SIQ does not require pathways that regulate DTQ}

Two classes of neurons are known to be required for normal quiescence during DTQ: the paired RIA neurons, which release the neuropeptide NLP-22, and the RIS neuron, which requires the AP2 transcription factor APTF-1 (Nelson et al., 2013; Turek et al., 2013). The ALA neuron, which secretes the neuropeptides encoded by $f l p-13$, is the only neuron known to be required for SIQ (Van Buskirk and Sternberg, 2007; Hill et al., 2014; Nelson et al., 2014) (Fig. 1A). Although SIQ and DTQ are behaviorally indistinguishable, it is unclear to what extent there is overlap between the mechanisms of behavioral quiescence during these states.

Although $f l p-13$ mutants have defective feeding and locomotion quiescence after cellular stress induction, their quiescence during larval transitions is normal (Nelson et al., 2014). To further compare the mechanisms of quiescence during DTQ and SIQ, we examined stress-induced feeding quiescence in mutants with defective quiescence during larval transitions. Although we detected differences in SIQ feeding quiescence between wild-type worms and $f l p-13$ mutants, neither $n l p-22$ mutants nor aptf-1 mutants displayed a defect in SIQ feeding quiescence, demonstrating that these DTQ-promoting factors are not required for quiescence during SIQ (Fig. 1B). Therefore, some factors required for quiescence during SIQ are not necessary for quiescence during DTQ and vice versa.

\section{Overexpression of $f l p-13$ or $n l p-22$ neuropeptide genes inhibits feeding and locomotion}

We next sought to identify conserved pathways that regulate quiescence downstream of the ALA and RIA interneurons during
SIQ and DTQ, respectively. Quiescence during SIQ requires the release of the FMRFamide-like FLP-13 neuropeptides from the ALA interneuron (Nelson et al., 2014) and quiescence during DTQ requires the release of the NLP-22 neuropeptide, which is structurally similar to the mammalian neuropeptide Neuromedin S, from the RIA interneuron. $n l p-22$ mRNA cycles in phase with mRNA of lin-42 (Jeon et al., 1999), the C. elegans homolog of the PERIOD gene, and an $n l p-22$ loss-of-function mutation decreases quiescence during DTQ (Nelson et al., 2013). Likewise, $f l p-13$ mRNA is increased after organismal stress and a $f l p-13$ loss-of-function mutation decreases quiescence during SIQ (Nelson et al., 2014; Fig. 1B).

We conditionally overexpressed these neuropeptides under control of the heat shock promoter (Phsp-16.2::flp-13 and $P h s p-16.2:: n l p-22)$ to robustly induce the quiescent behavioral states mimicking SIQ and DTQ (Nelson et al., 2013, 2014). This approach, similar to one recently used to study somnogenic neuropeptides in zebrafish (Woods et al., 2014), was selected for four reasons. First, in contrast to chronic loss-of-function experiments using genetic mutants, these conditional overexpression experiments are not subject to redundancy, compensation, or other developmental or physiological defects that may be part of the loss-of-function phenotype. Second, expressing the neuropeptides at supraphysiological levels is likely to activate all or nearly all of the receptors of these neuropeptides, so their effects will be limited only by the expression patterns of their receptors. Third, prolonged overexpression of the somnogenic peptides provides the experimental advantage of inducing a behavioral state lasting longer than the endogenous behavior, facilitating the identification of defects in these behaviors and characterization of downstream signaling pathways. Finally, the temporal control afforded by this conditional approach allowed us to compare quiescence induced by the two peptides in the same early adult stage, minimizing effects of developmental time on behavior. It is important to note that, whereas $f l p-13$ and $n l p-22$ have been implicated in SIQ and DTQ, respectively, it is unlikely that overexpression of these neuropeptide genes faithfully recapitulates all aspects of these sleep-like states. 
A

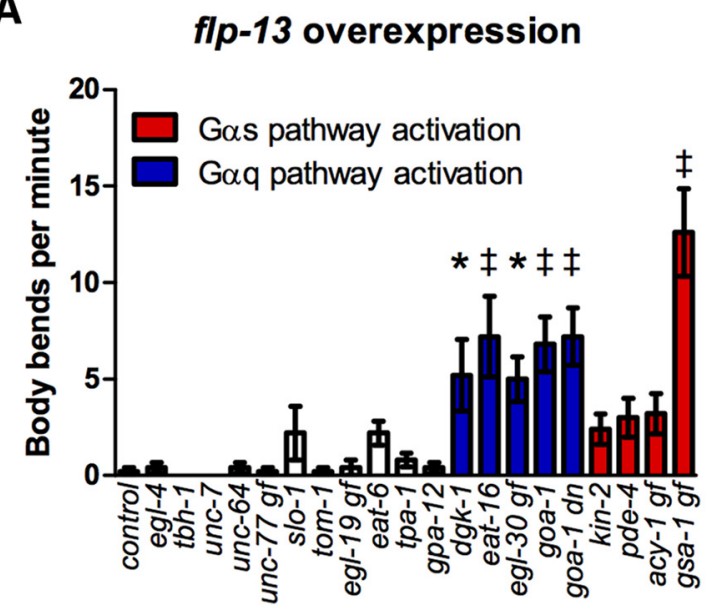

B

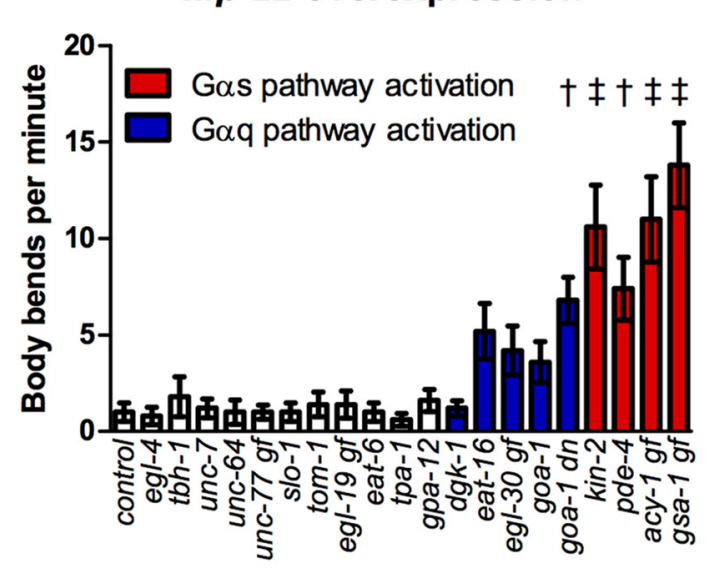

C

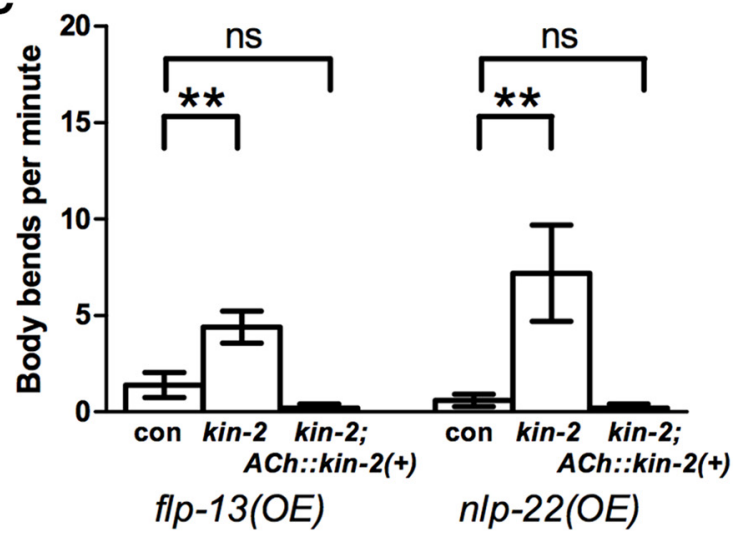

Figure 3. Activation of $\mathrm{G} \alpha \mathrm{q}$ or $\mathrm{G} \alpha$ s pathways impairs locomotion quiescence caused by flp-13 or $n / p$-22 overexpression. $\boldsymbol{A}$, Mutations that increase $\mathrm{G} \alpha q$ or $\mathrm{G} \alpha$ s signaling impair locomotion quiescence after flp-13 overexpression. $\boldsymbol{B}$, Mutations that increase $\mathrm{G} \alpha \mathrm{q}$ or $\mathrm{G} \alpha$ s signaling impair locomotion quiescence after $n / p$-22 overexpression. $\boldsymbol{A}$ and $\boldsymbol{B}$, Each bar represents the mean \pm SEM of body bends for 12-15 worms during a $20 \mathrm{~s}$ window. Each bar represents the data obtained for a different mutant strain containing the designated overexpression transgene. For detailed genotypes and data, see Table 2. gf, Gain-of-function mutation; dn, dominant-negative mutation; the others are loss-of-function mutations. Statistical significance was calculated using one-way ANOVA followed by Dunnett's multiple-comparison tests. ${ }^{*} p<$ $0.05, \dagger p<0.01, \neq p<0.001$. C, Rescuing kin-2 function in cholinergic neurons using the unc-17 promoter rescues the effects of the kin- 2 mutation on locomotion quiescence after flp-13 or $n / p-22$ overexpression. Con, flp-13 overexpression and $n / p-22$ overexpression control strains NQ570 or NQ251, respectively. $n=13-15$. Each bar represents mean \pm SEM. Statistical significance was calculated using one-way ANOVA followed by Dunnett's multiple-comparison tests. ${ }^{*} p<0.05,{ }^{* *} p<0.01,{ }^{* * *} p<0.001$.
Since SIQ is triggered by acute activation of the ALA neuron by heat shock, it is possible that the somnogenic effects of overexpressing these neuropeptide genes using the heat-shockinducible promoter are affected by ALA activation and the quiescence we observe does not reflect purely the somnogenic actions of the neuropeptides. Although we attempt to avoid effects of SIQ in our neuropeptide overexpression experiments by observing the animals at least $2 \mathrm{~h}$ after heat exposure and by inducing gene expression with a less stressful $33^{\circ} \mathrm{C}$ stimulus (Nelson et al., 2014), it remains possible that residual effects of SIQ influence the behavior of these animals. To test for this possibility, we overexpressed $n l p-22$ and $f l p-13$ in the ceh-17 mutant background, which lacks a functional ALA neuron (Pujol et al., 2000). We found that worms with a ceh-17 mutation were indistinguishable from controls $2 \mathrm{~h}$ after transgene induction with respect to both locomotion (nlp-22 overexpression: control: $1.0 \pm 0.2$ body bends per minute (bbpm), ceh-17: $1.6 \pm 0.3$ bbpm, $p=0.51$; flp- 13 overexpression: control: $0.6 \pm 0.2 \mathrm{bbpm}$, ceh-17: $1.0 \pm 0.2 \mathrm{bbpm}, p=0.54$; mean \pm SEM, $n=15)$ and feeding (nlp-22 overexpression: control: $30.6 \pm 4$ pumps per minute (ppm), ceh-17: $15.2 \pm 1.9$ ppm, $p=0.26$; flp-13 overexpression: control: $20.4 \pm 4.1 \mathrm{ppm}$, ceh-17: $16.2 \pm 2.1 \mathrm{ppm}, p=$ 0.72 ; mean \pm SEM, $n=15$ ), demonstrating that ALA activation is not required for the quiescence observed after $f l p-13$ or $n l p-22$ overexpression.

Activation of the $\mathrm{G} \alpha \mathrm{q}$ or $\mathrm{G} \alpha$ s pathways inhibits both $f l p-13-$ and $n l p$-22-induced locomotion quiescence

To identify conserved genes that regulate locomotion quiescence induced by overexpression of $f l p-13$ or $n l p-22$, we crossed strains overexpressing these neuropeptides into strains containing mutations in candidate genes with vertebrate homologs. Candidate genes were those that cause increased neurotransmitter release, increased membrane excitability, hyperactive locomotion, defective behavioral quiescence, or resistance to anesthetics. We focused in particular on strains with increased neurotransmitter release due to increased $\mathrm{G} \alpha \mathrm{q}$ and $\mathrm{G} \alpha$ s signaling (Fig. 2, adapted from Perez-Mansilla and Nurrish, 2009), since these mutants show hyperactive locomotion and some have defects in DTQ locomotion quiescence (Belfer et al., 2013; Iwanir et al., 2013; Schwarz and Bringmann, 2013; Singh et al., 2014), and therefore they might be resistant to the effects of somnogenic neuropeptides.

The G $\alpha \mathrm{q}$ signaling pathway acts antagonistically to G $\alpha$ o signaling in C. elegans and promotes neurotransmitter release by increasing diacylglycerol (DAG) levels (Miller et al., 1999), whereas the Gas pathway acts downstream of DAG to increase neurotransmitter release (Reynolds et al., 2005). Hyperactivation of the G $\alpha$ q signaling pathway can be achieved either directly, using a gain-of-function mutation in the $\mathrm{G} \alpha \mathrm{q}$ gene egl-30 (Doi and Iwasaki, 2002), or indirectly, using loss-of-function mutations in the G $\alpha$ o gene goa-1 (Miller et al., 1996), the regulator of G-protein signaling gene eat-16 (Hajdu-Cronin et al., 1999), or the diacylglycerol kinase theta gene $d g k-1$ (Miller et al., 1999). Hyperactivation of the $G \alpha$ s signaling pathway can also be achieved either directly, using gain-of-function mutations in the G $\alpha$ s gene gsa-1 (Schade et al., 2005) or the adenylate cyclase type IX gene acy-1 (Schade et al., 2005), or indirectly, using loss-offunction mutations in the phosphodiesterase-4 gene pde-4 (Charlie et al., 2006) or the cAMP-dependent protein kinase (PKA) regulatory subunit gene kin-2 (Schade et al., 2005).

We also examined strains with mutations that increased neurotransmitter release by other means, including loss-of-function 
Table 2. Detailed data for Figures 3 and 4

\begin{tabular}{|c|c|c|c|c|c|c|c|c|c|c|c|c|c|c|c|}
\hline \multirow[b]{2}{*}{ Gene mutated } & \multirow[b]{2}{*}{ Change in function } & \multicolumn{7}{|c|}{ Mutant; flp-13 overexpression } & \multicolumn{7}{|c|}{ Mutant; $n / p-22$ overexpression } \\
\hline & & ppm & SD & Sig & bbpm & SD & Sig & $N$ & ppm & SD & Sig & bbpm & SD & Sig & $N$ \\
\hline gsa-1 & Gain & 133.5 & 55.6 & $* * *$ & $\underline{13.5}$ & $\underline{8.4}$ & **** & 14 & 31.6 & 24.0 & ns & 13.8 & 8.5 & $* * *$ & 15 \\
\hline$a c y-1$ & Gain & 69.6 & 69.1 & * & 3.2 & $\underline{4.0}$ & $\underline{\mathrm{ns}}$ & 15 & 39.6 & 25.6 & ns & 11.0 & 8.5 & $* * *$ & 15 \\
\hline pde-4 & Loss & 130.5 & 74.8 & $* * *$ & $\underline{3.8}$ & $\underline{4.1}$ & $\underline{\text { ns }}$ & 12 & 22.2 & 28.5 & ns & 7.4 & 6.3 & ** & 15 \\
\hline kin-2 & Loss & 132.6 & 61.4 & $* * *$ & $\underline{2.4}$ & $\underline{3.0}$ & $\underline{\text { ns }}$ & 15 & 22.0 & 14.9 & ns & 10.6 & 8.4 & $* * *$ & 15 \\
\hline goa-1 & DN & 91.6 & 64.1 & $* * *$ & 6.8 & 5.5 & $* * *$ & 15 & 24.0 & 15.3 & ns & 3.6 & 4.1 & ns & 15 \\
\hline goa-1 & Loss & 103.0 & 55.7 & $* * *$ & 7.2 & 5.8 & $* * *$ & 15 & 23.4 & 27.9 & ns & 6.8 & 4.6 & $* *$ & 15 \\
\hline egl-30 & Gain & 78.4 & 57.1 & $* *$ & 5.0 & 4.5 & * & 15 & 38.8 & 27.1 & ns & 4.2 & 4.9 & ns & 15 \\
\hline eat-16 & Loss & 71.2 & 44.6 & * & 7.2 & 8.1 & $* * *$ & 15 & 3.6 & 3.6 & ns & 5.2 & 5.6 & ns & 15 \\
\hline dgk-1 & Loss & 136.4 & 43.7 & $* * *$ & 5.2 & 7.2 & * & 15 & 41.4 & 46.7 & ns & 1.2 & 1.5 & ns & 15 \\
\hline gpa-12 & Loss & 87.8 & 85.5 & $* * *$ & 0.4 & 1.1 & ns & 15 & 11.6 & 9.5 & ns & 1.6 & 2.2 & ns & 15 \\
\hline tpa-1 & Loss & 64.2 & 52.7 & * & 0.8 & 1.4 & ns & 15 & 21.6 & 18.6 & ns & 0.6 & 1.2 & ns & 15 \\
\hline eat-6 & Loss & 59.6 & 34.6 & ns & 2.4 & 2.4 & ns & 14 & 36.8 & 34.6 & ns & 1.0 & 1.9 & ns & 15 \\
\hline egl-19 & Gain & 90.4 & 64.4 & $* * *$ & 0.4 & 1.5 & ns & 15 & 16.0 & 13.2 & ns & 1.4 & 2.7 & ns & 15 \\
\hline tom-1 & Loss & 24.2 & 41.8 & ns & 0.2 & 0.8 & ns & 15 & 24.6 & 31.4 & ns & 1.4 & 2.5 & ns & 15 \\
\hline slo-1 & Loss & 32.6 & 25.8 & ns & 2.2 & 5.4 & ns & 15 & 50.2 & 50.6 & ns & 1.0 & 1.9 & ns & 15 \\
\hline unc-77 & Gain & 33.8 & 41.9 & ns & 0.2 & 0.8 & ns & 15 & 32.8 & 27.5 & ns & 1.0 & 1.5 & ns & 15 \\
\hline unc-64 & Neomorph & 27.0 & 34.8 & ns & 0.4 & 1.1 & ns & 14 & 16.8 & 18.6 & ns & 1.0 & 2.4 & ns & 15 \\
\hline unc-7 & Loss & 87.2 & 57.6 & $* * *$ & 0.0 & 0.0 & ns & 15 & 27.8 & 16.8 & ns & 1.2 & 1.9 & ns & 15 \\
\hline$t b h-1$ & Loss & 8.2 & 23.9 & ns & 0.0 & 0.0 & ns & 15 & 45.8 & 42.1 & ns & 1.8 & 4.1 & ns & 15 \\
\hline egl-4 & Loss & 9.4 & 24.2 & ns & $\underline{0.4}$ & $\underline{1.1}$ & $\underline{\text { ns }}$ & 15 & 37.4 & 34.1 & ns & 0.8 & 1.8 & ns & 15 \\
\hline None & & 5.8 & 12.2 & & 0.2 & 0.8 & & 15 & 28.0 & 30.9 & & 1.0 & 1.9 & & 15 \\
\hline
\end{tabular}

$\mathrm{DN}$, Dominant-negative; $\mathrm{ppm}$, indicates pumps/min; bbpm, indicates body bends/min. Underlines indicate twitching phenotype.

${ }^{*} p<0.05,{ }^{* *} p<0.01,{ }^{* * *} p<0.001$, by Dunnett's multiple-comparison test after one-way ANOVA.

mutations in the tomosyn gene tom-1 (Dybbs et al., 2005) and the BK channel gene slo-1 (Wang et al., 2001), as well as mutations that generally increased membrane excitability, including a gainof-function mutation in the L-type $\mathrm{Ca}^{2+}$ channel gene egl-19 (Lee et al., 1997) and a loss-of-function mutation in the $\mathrm{Na}^{+} / \mathrm{K}^{+}$ transporter $\alpha$-subunit gene eat-6 (Davis et al., 1995). We also tested strains with mutations that confer resistance to anesthesia, including a gain-of-function mutation in the NALCN channel subunit gene unc-77 (Humphrey et al., 2007; Morgan et al., 2007; Yeh et al., 2008), a loss-of-function mutation in the innexin gene unc-7 (Starich et al., 1996), and a neomorphic mutation affecting the syntaxin gene unc-64 (van Swinderen et al., 1999). Finally, we tested strains with mutations that caused defects in various types of behavioral quiescence, including loss-of-function mutations in the cGMP-dependent protein kinase (PKG) gene egl-4 (Raizen et al., 2008), the G $\alpha 12$ gene gpa-12 (van der Linden et al., 2003), the protein kinase $\mathrm{C}$ epsilon (PKC- $\varepsilon$ ) gene tpa-1 (van der Linden et al., 2003), and the tyramine $\beta$-hydroxylase gene $t b h-1$ (Alkema et al., 2005). Table 1 lists all mutants tested and their effects on relevant signaling pathways and cell physiology.

Mutations that increase $\mathrm{G} \alpha \mathrm{q}$ or $\mathrm{G} \alpha$ s signaling suppressed the locomotion quiescence induced by overexpression of either flp-13 or $n l p-22$ (Fig. $3 A, B$, Table 2). However, whereas overexpression of $n l p-22$ in mutants with activated $G \alpha$ s signaling caused qualitatively normal locomotion, overexpression of $f l p-13$ in the same mutants caused aberrant locomotion characterized by uncoordinated twitches and accordion-like contractions. G $\alpha \mathrm{q}$ pathway genes are expressed in neurons, but not in body wall muscles (Nurrish et al., 1999; Bastiani et al., 2003), and cholinergic neuron stimulation during DTQ causes contraction of body wall muscle (Dabbish and Raizen, 2011), suggesting that FLP-13 and NLP-22 neuropeptides both act on neurons to inhibit locomotion.

To test whether these neuropeptides act via cholinergic neurons to regulate locomotion, we rescued the function of kin-2, the PKA regulatory subunit, in cholinergic neurons using the $u n c-17$ promoter and assessed the effect of neuropep- tide overexpression on locomotion. We found that, after restoring kin-2 function in cholinergic neurons, locomotion was strongly inhibited after overexpression of either neuropeptide gene (Fig. 3C), demonstrating that decreased PKA signaling in cholinergic neurons is important for inhibiting locomotion downstream of these neuropeptides. However, because we observed different locomotion phenotypes after overexpressing $f l p-13$ or $n l p-22$ in backgrounds with activated $\mathrm{G} \alpha$ s signaling, these neuropeptides likely act on different molecular targets and/or different subsets of cholinergic neurons.

\section{Feeding quiescence induced by $f l p-13$ overexpression, but not $n l p-22$ overexpression, is suppressed by activation of the $\mathrm{G} \alpha \mathrm{q}$ or $\mathrm{G} \alpha$ s pathways}

C. elegans feeds by rhythmic contraction of its pharynx, a neuromuscular pump possessing 20 neurons of 14 types (Albertson and Thomson, 1976). To identify conserved signaling pathways that regulate feeding quiescence downstream of $f l p-13$ and $n l p-22$, we overexpressed these neuropeptide genes in the mutant backgrounds described above and in Table 1. As with locomotion quiescence, feeding quiescence induced by $f l p-13$ overexpression was strongly suppressed by mutations that increase neurotransmitter release by activating either the $\mathrm{G} \alpha \mathrm{q}$ or $\mathrm{G} \alpha$ s signaling pathways (Fig. $4 A$, Table 2), which are present in all or nearly all neurons (Ségalat et al., 1995; Korswagen et al., 1997; Bastiani et al., 2003). In these mutants, feeding rates were substantially higher than the control feeding rate, even though in the absence of neuropeptide overexpression, many of these strains feed at rates similar to that of the control (Song and Avery, 2012). In addition, some mutations that increase neurotransmitter release by other mechanisms or confer resistance to anesthesia also suppressed the feeding quiescence caused by $f l p-13$ overexpression (Fig. $4 A$ ). In contrast, none of the mutants tested suppressed the feeding quiescence induced by $n l p-22$ overexpression (Fig. $4 B$ ). These results indicate that FLP-13 and NLP-22 neuropeptides promote feeding quiescence via distinct molecular mechanisms. 
A

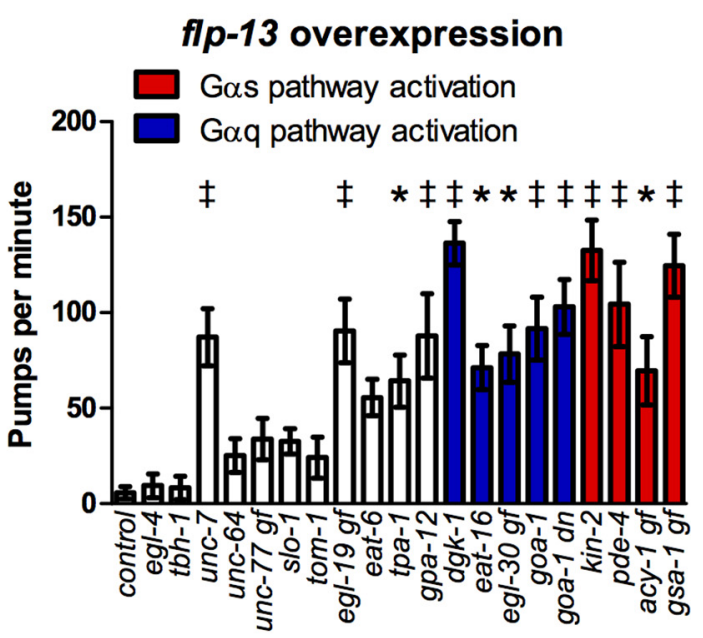

B

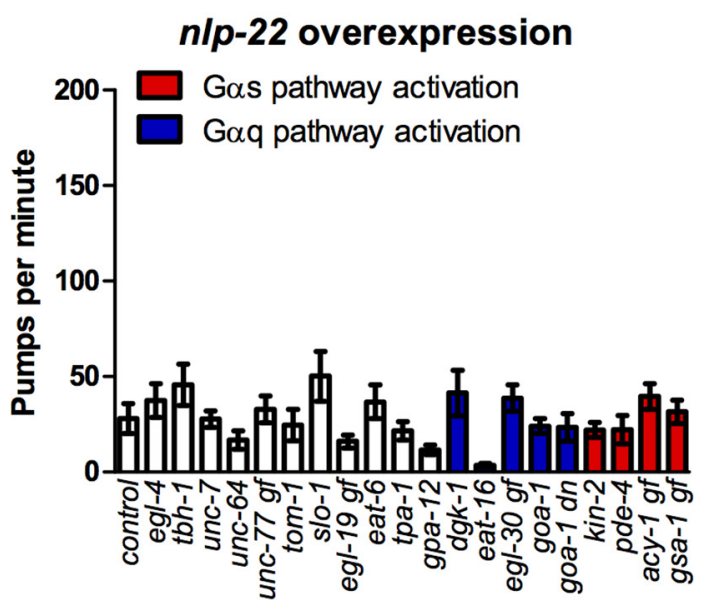

Figure 4. Activation of $\mathrm{G} \alpha \mathrm{q}$ or $\mathrm{G} \alpha$ s pathways impairs feeding quiescence caused by flp-13 overexpression, but not that caused by $n / p-22$ overexpression. $\boldsymbol{A}$, Mutations that increase $\mathrm{G} \alpha q$ or $\mathrm{G} \alpha$ s signaling impair feeding quiescence after $f l p-13$ overexpression relative to the control flp-13 overexpression strain. $\boldsymbol{B}$, Mutations that increase $\mathrm{G} \alpha \mathrm{q}$ or $\mathrm{G} \alpha$ s signaling do not affect feeding rate after $n l p-22$ overexpression relative to the control $n / p$ - 22 overexpression strain. $g$, Gain-of-function mutation; dn, dominant-negative mutation; the others are loss-of-function mutations. Each bar represents the mean \pm SEM of pharyngeal pumps for 12-15 worms during a $20 \mathrm{~s}$ window for a different mutant strain containing the designated overexpression transgene. Statistical significance was calculated using a one-way ANOVA followed by Dunnett's multiple-comparison tests. ${ }^{*} p<0.05, \uparrow p<0.01, \neq p<0.001$.

FLP-13 inhibits feeding by acting on neurons; NLP-22 inhibits feeding downstream of neurons

Because $f l p-13$-induced feeding quiescence is suppressed by mutations that increase neurotransmitter release, but nlp-22induced feeding quiescence is not, we hypothesized that the FLP-13 neuropeptides promote feeding quiescence by acting on the nervous system and that the NLP-22 neuropeptide promotes feeding quiescence by acting directly on the pharyngeal muscle. To test this hypothesis, we rescued the function of kin-2, the PKA regulatory subunit, in cholinergic neurons and assessed the effect of neuropeptide overexpression on feeding rate. We found that restoring kin-2 function in cholinergic neurons restored pumping levels after $f l p-13$ overexpression to that of the control, whereas restoring kin-2 function in cholinergic neurons after $n l p-22$ overexpression did not affect feeding rate (Fig. 5A).
Three classes of pharyngeal cholinergic motor neurons, the paired MC and M2 neurons and the single M4 neuron, stimulate pharyngeal pumping (Avery and Horvitz, 1989; Raizen et al., 1995; Trojanowski et al., 2014). Based on the above results, we predicted that $f l p$-13-induced feeding quiescence, but not $n l p-22$ induced feeding quiescence, could be overcome by perturbations that excite pharyngeal cholinergic motor neurons. To test this hypothesis, we used both pharmacological and optogenetic approaches.

First, we tested the effects of the neuromodulator serotonin (5-hydroytryptamine or 5-HT) on feeding quiescence induced by flp-13 or $n l p-22$ overexpression. 5-HT stimulates pharyngeal pumping primarily via the SER-7 5-HT receptor and downstream G $\alpha$ s signaling in pharyngeal cholinergic motor neurons (Hobson et al., 2006; Song and Avery, 2012). Therefore, the effects of neuropeptides that promote feeding quiescence by acting on or upstream of pharyngeal motor neurons should be suppressed by 5-HT, whereas the effects of neuropeptides that act downstream of the motor neurons should be unaffected by $5-\mathrm{HT}$. We found that $n l p$-22-induced feeding quiescence was not suppressed by the excitatory effects of $5-\mathrm{HT}$, consistent with the NLP-22 acting downstream of the pharyngeal motor neurons (Fig. $5 B$ ). In contrast, $f l p-13$-induced feeding quiescence was fully suppressed by $5-\mathrm{HT}$, consistent with the FLP-13 neuropeptides acting on or upstream of the pharyngeal motor neurons (Fig. 5B).

An alternative explanation for these differential effects that would be consistent with both neuropeptides suppressing feeding by the same mechanisms is that $n l p-22$ is overexpressed at higher levels than $f l p-13$ and that 5-HT can overcome mild overexpression, but not strong overexpression. We tested this possibility two ways, both making use of the fact that the transgenes expressing the neuropeptides were under the control of a heatinducible promoter and we could thus vary the degree of transgene overexpression. First, we induced different degrees of expression of each neuropeptide transgene by varying the duration of the animals' exposure to $33^{\circ} \mathrm{C}$. In the presence of food, an environmental stimulant to feeding rate, but in the absence of exogenous 5-HT, overexpression of either neuropeptide gene caused a similar reduction in feeding rate $2-3 \mathrm{~h}$ after heat exposure that was a function of the duration of prior heat exposure (and thus a function of neuropeptide expression; Fig. $5 C$ ). In contrast, in the presence of exogenous 5-HT, but not food, overexpression of $f l p-13$ and $n l p-22$ produced different effects on feeding rate. Similar to its effect in the presence of food, $n l p-22$ overexpression caused a dose-dependent reduction in feeding rate in the presence of 5-HT. In contrast, even strong overexpression of $f l p-13$ failed to inhibit feeding in the presence of 5-HT (Fig. 5D).

As a second way of testing if the different effects of 5-HT after overexpressing $n l p-22$ or $f l p-13$ were due to differential overexpression of transgenes, we exposed the animals to $29^{\circ} \mathrm{C}$ instead of $33^{\circ} \mathrm{C}$ for $30 \mathrm{~min}$ to induce a lower level of transgene expression. This lower induction temperature had the additional advantage of being less likely to trigger quiescence on the basis of acute heat exposure (Nelson et al., 2014). Animals carrying transgenes with the heat shock promoter driving either $f l p-13$ or $n l p-22$ overexpression showed feeding quiescence $2 \mathrm{~h}$ after this $30 \mathrm{~min} 29^{\circ} \mathrm{C}$ heat exposure (Phsp-16.2::flp-13: $182.1 \pm 8.7 \mathrm{ppm}$ before heat, $20.1 \pm 8.6$ ppm after heat, $p<0.001$; Phsp-16.2::nlp-22: $145.2 \pm$ 5.2 ppm before heat, $9.3 \pm 3.6$ ppm after heat, $p<0.001$; mean \pm SEM, $n=10$ ), demonstrating that both transgenes were expressed at sufficiently high levels to induce quiescence even at this milder activation temperature. At an earlier time point (35 min) 
A

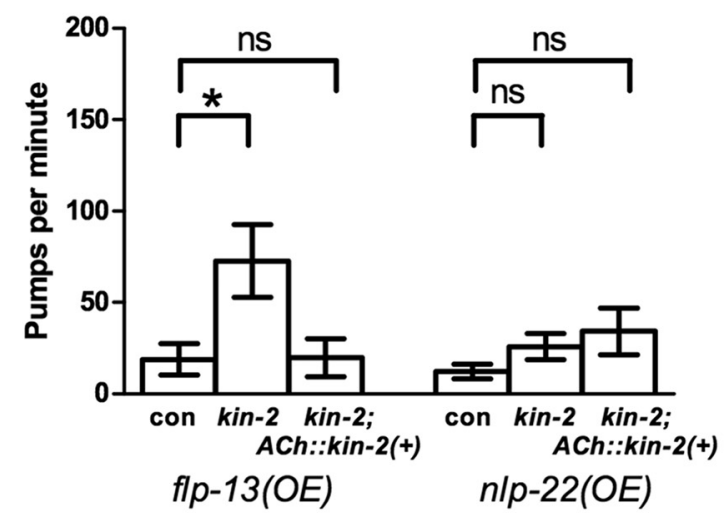

C

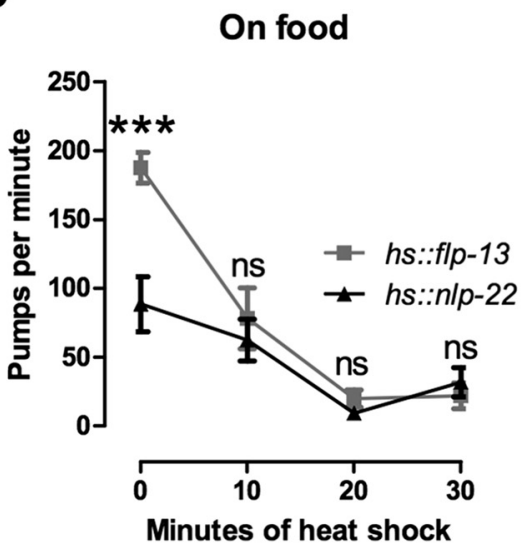

B

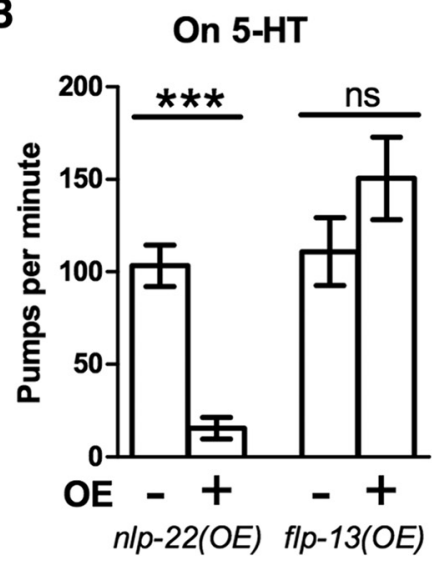

D

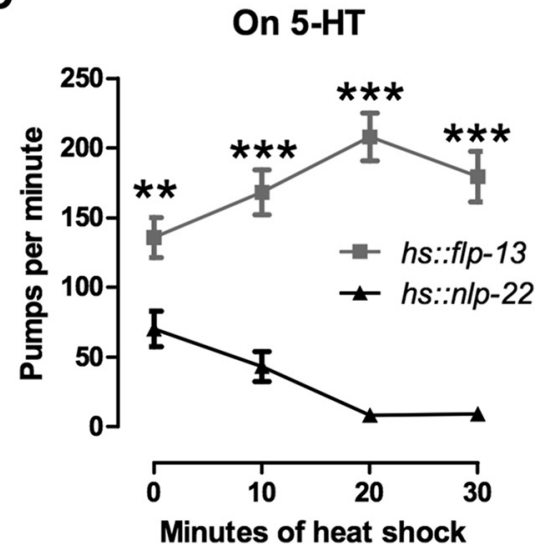

E

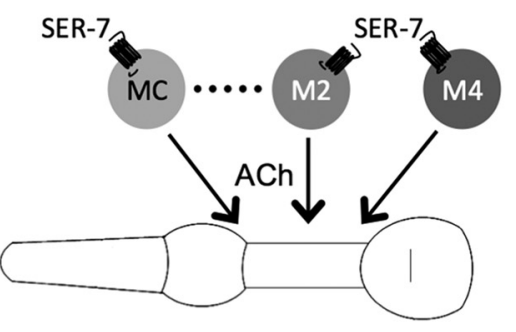

$\mathbf{F}$

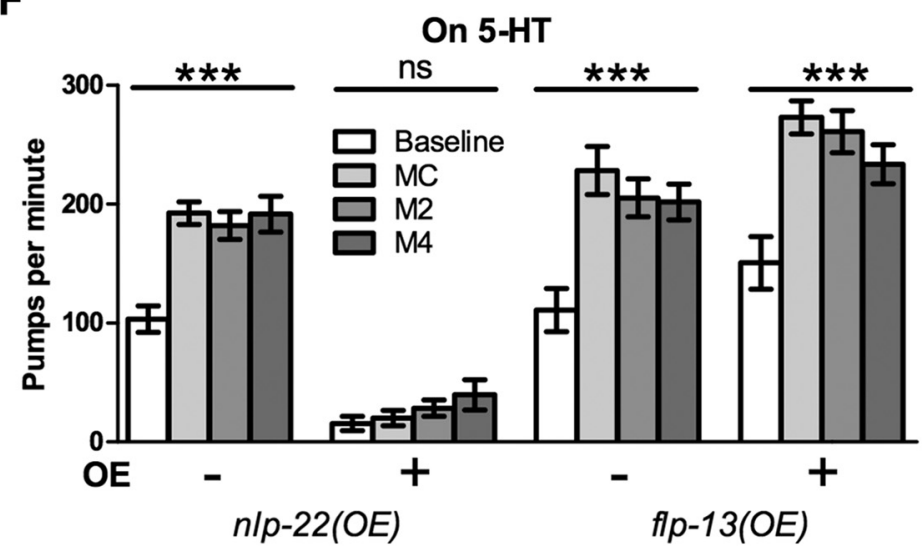

Figure 5. FLP-13 inhibits pharyngeal pumping by acting on neurons, but NLP-22 inhibits feeding downstream of motor neuron excitation. $A$, Rescuing kin-2 function in cholinergic neurons using the unc- 17 promoter rescues the effect of the $k i n-2$ mutation on feeding quiescence induced by flp-13 overexpression, but does not affect feeding quiescence induced by $n / p-22$ overexpression. Con, flp-13 overexpression and $n / p-22$ overexpression control strains NQ570 or NQ251 respectively. $n=13-15$. Each bar represents mean \pm SEM. Statistical significance was calculated using one-way ANOVA followed by Dunnett's multiple-comparison tests. $\boldsymbol{B}$, In immobilized worms, 5 -HT blocks the inhibitory effect of flp- 13 overexpression on feeding, but not that of $n / p-22$ overexpression on feeding. $n=10$. Each bar represents mean \pm SEM. Statistical significance was calculated using Student's $t$ test. $C$, flp- 13 overexpression and $n / p-22$ overexpression cause similar effects on feeding in worms in the presence of food when overexpressed to similar degrees. $n=9-15$. Each point represents mean \pm SEM. Statistical significance was calculated using a two-way ANOVA. $\boldsymbol{D}$, The difference in the effects of 5 -HT on feeding rate in immobilized worms after flp- 13 overexpression and $n / p-22$ overexpression is not affected by the degree of neuropeptide overexpression. $n=9-15$. Each point represents mean \pm SEM. Statistical significance was calculated using a two-way ANOVA. $\boldsymbol{E}$, Schematic of the excitatory cholinergic pharyngeal neurons and SER-75-HT receptor. F, Optogenetic excitation of the pharyngeal cholinergic motor neurons MC, M2, and M4 stimulates pumping in immobilized worms after flp-13 overexpression, but not after $n / p-22$ overexpression. $n=10$. Each bar represents mean \pm SEM. Statistical significance was calculated using a one-way ANOVA. ${ }^{*} p<0.05,{ }^{* *} p<0.01,{ }^{* * *} p<0.001$. 


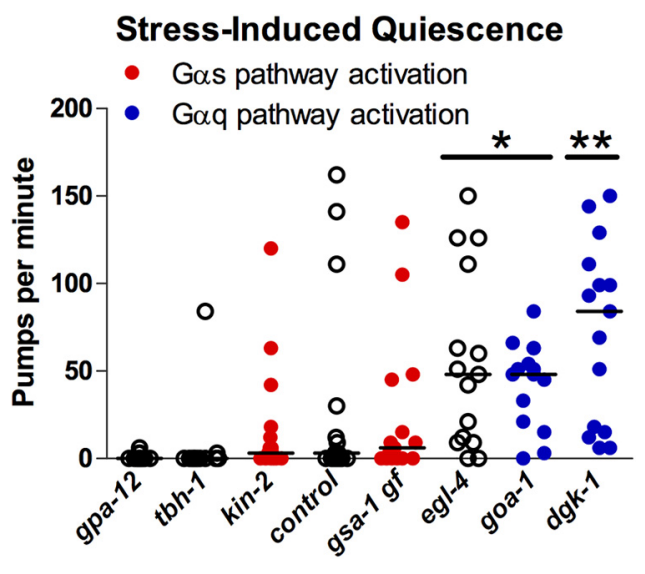

Figure 6. Activation of $\mathrm{G} \alpha \mathrm{q}$, but not $\mathrm{G} \alpha \mathrm{s}$, pathway impairs feeding quiescence during SIQ. Mutants with increased DAG levels due to activation of the $G \alpha q$ pathway have increased feeding during SIQ, but mutants with an activated $G \alpha$ s pathway do not. In addition, an egl-4 mutation impairs feeding quiescence during SIQ. Each point represents an observation from one worm and the horizontal bar represents the median of each group. $n=15$ for each group. Statistical significance was calculated using the Mann-Whitney test. ${ }^{*} p<0.05$, ${ }^{* *} p<0.01$.

after the same $30 \mathrm{~min} 29^{\circ} \mathrm{C}$ heat exposure, worms overexpressing $f l p-13$, but not worms overexpressing $n l p-22$, showed feeding quiescence (Phsp-16.2::flp-13: $181.2 \pm 8.7$ ppm before heat, $11.4 \pm 5.2$ ppm 35 min after heat, $p<0.001 ;$ Phsp-16.2::nlp-22: $145.2 \pm 5.2 \mathrm{ppm}$ before heat, $136.2 \pm 16.3 \mathrm{ppm} 35 \mathrm{~min}$ after heat, $p=0.61$; mean \pm SEM, $n=10)$. These observations suggest that the differential effects of 5-HT on feeding quiescence are not explained by reduced activation of the $f l p-13$ transgene relative to the $n l p-22$ transgene.

Next, we used an optogenetic approach to test where the NLP-22 and FLP-13 neuropeptides act in relation to depolarization of cholinergic pharyngeal motor neurons (Fig. 5E). Although 5-HT activates pumping via these neurons, optogenetic stimulation via the lightsensitive cation channel Channelrhodopsin-2 (ChR2) of individual cholinergic motor neurons in the presence of 5-HT induces an even greater increase in feeding rate during wake (Trojanowski et al., 2014). We stimulated single pharyngeal motor neurons and monitored resulting changes in feeding rate. We found that stimulation of any of the excitatory cholinergic neurons MC, M2, or M4 caused an increase in feeding rate after $f l p-13$ overexpression, but not after $n l p-22$ overexpression (Fig. 5F). These results further support the hypothesis that the FLP-13 neuropeptides act on or upstream of the pharyngeal cholinergic neurons, whereas the NLP-22 neuropeptide acts downstream of cholinergic neuron excitation, likely on the pharyngeal muscle.

\section{Feeding quiescence during SIQ is abolished by activation of}

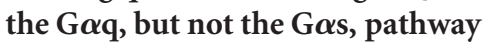

Having gained insight into the mechanisms through which the NLP-22 and FLP-13 neuropeptides control feeding, we next investigated whether feeding is regulated by similar mechanisms in their associated sleep-like states. Because we found that mutations that increase $\mathrm{G} \alpha$ s or $\mathrm{G} \alpha \mathrm{q}$ signaling suppressed flp-13induced feeding quiescence, we hypothesized that these mutations would also suppress feeding quiescence during SIQ. We found that mutations that increased $\mathrm{G} \alpha$ s signaling did not affect feeding quiescence during SIQ, whereas mutations that increased $\mathrm{G} \alpha \mathrm{q}$ signaling did suppress feeding quiescence during SIQ (Fig. 6). Therefore, activation of $\mathrm{G} \alpha$ s signaling suppresses feeding quiescence induced by $f l p-13$ overexpression, but does not suppress the feeding quiescence observed during SIQ, whereas activation of $\mathrm{G} \alpha \mathrm{q}$ signaling suppresses feeding quiescence after either flp-13 overexpression or during SIQ. These results suggest that other neurotransmitters released by ALA affect feeding quiescence during SIQ, perhaps by acting downstream of $\mathrm{G} \alpha$ s signaling.

We also found that a loss-of-function mutation in egl-4 (PKG) suppressed feeding quiescence during SIQ (Fig. 6), suggesting that EGL-4 acts downstream of or in parallel to ALA activation. Because the egl-4 mutation did not suppress feeding quiescence in response to $f l p-13$ overexpression (Fig. $4 A$, Table 2), egl-4 may be acting downstream of or in parallel to a neurotransmitter distinct from FLP-13 that is released from ALA. Alternatively, FLP-13 released by $f l p-13$ overexpression under the heat shock promoter may act on receptors that are not engaged by FLP-13 released from ALA. These possibilities are not mutually exclusive.

\section{The pharyngeal nervous system can excite feeding during SIQ but not DTQ}

Based on our results from animals overexpressing either $f l p-13$ or $n l p-22$, we hypothesized that feeding is inhibited at the level of the pharyngeal motor neurons during SIQ, whereas during DTQ feeding is inhibited downstream of motor neuron excitation. To test this hypothesis, we again used both pharmacological and optogenetic approaches. First, we placed worms in either SIQ or DTQ on agarose pads containing 5-HT to determine whether excitation of pharyngeal neurons with 5-HT could stimulate feeding during these states. We found that worms in SIQ, but not DTQ, pumped in the presence of 5-HT, suggesting that feeding quiescence during SIQ occurs at the level of or upstream of pharyngeal cholinergic motor neurons, whereas feeding is inhibited at a level downstream of pharyngeal cholinergic motor neuron during DTQ (Fig. 7A).

Absence of feeding induction by 5 -HT during DTQ could be explained by decreased 5-HT responsiveness during this state. Alternatively, it could be explained by reduced excitability of the motor neurons or by reduced excitability of pharyngeal muscle downstream of motor neuron excitation. To further delineate the circuit mechanism of feeding cessation during SIQ and DTQ, we optogenetically depolarized pharyngeal cholinergic motor neurons during these states. To minimize the effects of animal immobilization on behavior and to provide as strong an excitatory input to pumping as possible, we used wide-field blue light illumination to stimulate ChR2 in all cholinergic neurons in worms on bacterially seeded agar plates. As with nlp-22 overexpression, stimulation of cholinergic neurons did not result in feeding during DTQ (Fig. 7B). However, as with $f l p-13$ overexpression, cholinergic neuron stimulation caused feeding during SIQ. These results are consistent with NLP-22 inhibiting pharyngeal muscle during DTQ and FLP-13 inhibiting pharyngeal cholinergic motor neurons during SIQ.

\section{Pharyngeal muscle excitability is altered during DTQ}

Our result that depolarization of pharyngeal neurons during DTQ did not stimulate feeding suggests that feeding is inhibited at the level of the muscle during this state. However, another possible explanation is that neurotransmitter release is blocked during DTQ. To test directly whether feeding was inhibited at the level of the muscle during DTQ, we attempted to stimulate pharyngeal muscle optogenetically. We had difficulty expressing ChR2 in pharyngeal muscle, so instead we used the light-sensitive cation channel Chrimson (Klapoetke et al., 2014), which expressed well. The peak excitation wavelength of Chrimson is $\sim 590 \mathrm{~nm}$, but it retains adequate sensitivity (about 25\% of peak) to $473 \mathrm{~nm}$ blue light (Klapoetke et al., 2014), so we used the same laser and power to stimulate Chrimson as we did for ChR2. We found that optogenetic stimulation of pharyngeal muscle in- 
creased feeding rate during wake, but this effect was abolished during DTQ (Fig. 7C). Thus, even when pharyngeal muscle was optogenetically depolarized, it did not contract, suggesting that either the coupling between excitation and contraction is altered during DTQ or that $\mathrm{Ca}^{2+}$ levels in the muscle are not rising sufficiently to generate contractions.

To test whether this uncoupling between muscle depolarization and contraction is upstream or downstream of increased $\mathrm{Ca}^{2+}$ levels, we imaged $\mathrm{Ca}^{2+}$ levels in the metacorpus region of the pharyngeal muscle (Avery and You, 2012) using the genetically encoded $\mathrm{Ca}^{2+}$ sensor GCaMP6s (Chen et al., 2013). During wake, we detected fluctuations in GCaMP6s fluorescence in the metacorpus (Fig. 7D,E); such $\mathrm{Ca}^{2+}$ transients are associated with pharyngeal pumps (Kerr et al., 2000; Akerboom et al., 2013). These fluctuations in GCaMP6s fluorescence were absent during DTQ, demonstrating that $\mathrm{Ca}^{2+}$ levels in the muscle do not oscillate during DTQ (Fig. 7D,F). $\mathrm{Ca}^{2+}$ transients during DTQ were undetectable even when pharyngeal muscle was optogenetically depolarized (Fig. 7D), demonstrating that pharyngeal excitability is fundamentally altered during DTQ such that $\mathrm{Ca}^{2+}$ levels cannot rise and trigger muscle contraction.

\section{Discussion}

Our results show that, despite the behavioral similarities of DTQ and SIQ, the quiescence-inducing mechanisms downstream of neuropeptide release are distinct in these states. Overexpression of the DTQ-associated neuropeptide gene $n l p-22$ inhibits feeding via action on pharyngeal muscle and acts on the nervous system to inhibit locomotion. In contrast, the SIQ-associated FLP-13 neuropeptides inhibit feeding via the pharyngeal nervous system and inhibit locomotion by acting on the nervous system through a different mechanism from that of NLP-22 (Fig. 8). Further, we found that stimulation of pharyngeal motor neurons excites feeding during SIQ but not during DTQ, and even direct stimulation of pharyngeal muscle does not excite feeding during DTQ. It is important to note that we have focused on two particular behavioral programs observed during sleep in all animals: quiescence of feeding and locomotion. Other aspects of sleep behavior, such as an elevated sensory arousal threshold, were not studied here and may be regulated by mechanisms different from those regulating feeding and locomotion quiescence.

Nevertheless, to our knowledge this is the first in vivo demonstration that a nonmammalian animal can express mechanistically distinct types of quiescence during sleep-like states. These
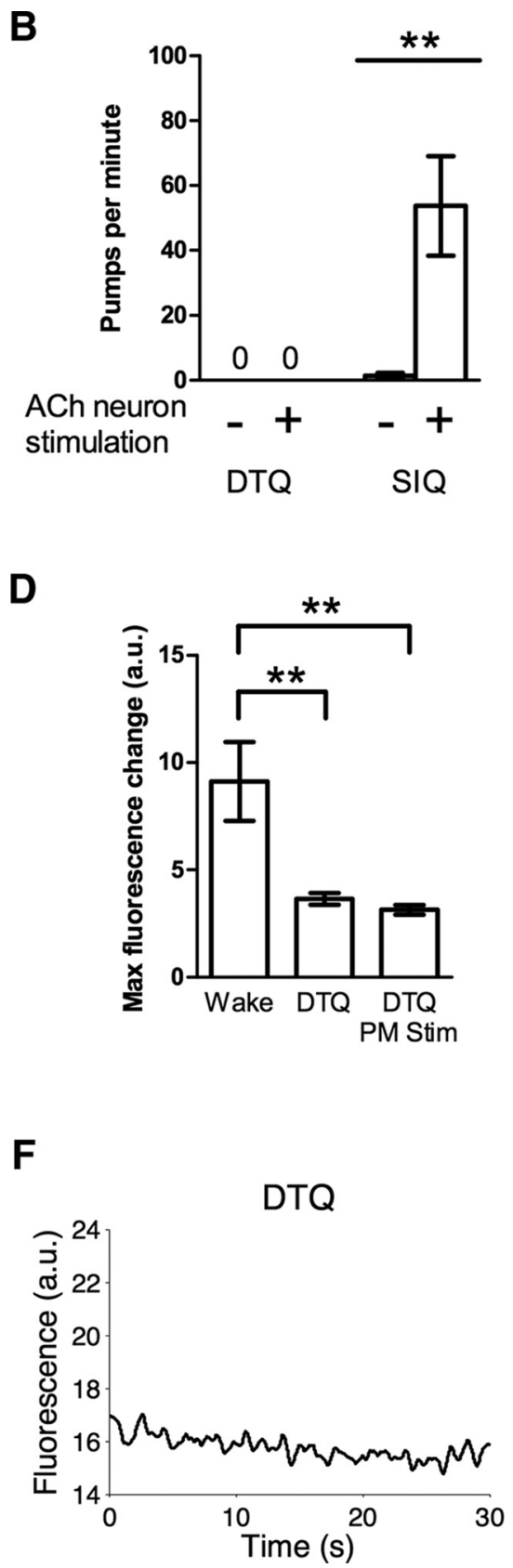

Figure 7. The pharyngeal nervous system can excite feeding during SIQ, but not during DTQ.A, $10 \mathrm{~mm} 5-\mathrm{HT}$ stimulates feeding during SIQ, but not during DTQ. $n=8-10 . B$, Optogenetic excitation of all cholinergic pharyngeal neurons ( $A C h N$ ) by wide-field fluorescence stimulates feeding in worms on bacterially seeded agar plates during SIQ, but not during DTQ. $n=13$ for each group. C, Optogenetic excitation of pharyngeal muscle stimulates feeding in the presence of $10 \mathrm{~mm} 5-\mathrm{HT}$ during wake, but not during DTQ. $n=10 . D_{1} \mathrm{Ca}^{2+}$ transients are absent from pharyngeal muscle during DTQ and cannot be stimulated by muscle excitation. The difference between maximum and minimum GCaMP6s intensity of a region of the metacorpus of the pharynx during an $\sim 30 \mathrm{~s}$ interval was calculated for each condition to measure the magnitude of $\mathrm{Ca}^{2+}$ transients. $n=10 . E, G C a M P 6 s$ fluorescence from a region of the metacorpus from one representative worm during wake. $F$, GCaMP6s fluorescence from a region of the metacorpus from one representative worm during DTQ. a.u., Arbitrary units in D-F. Statistical significance was calculated using Student's $t$ test. ${ }^{*} p<0.05,{ }^{* *} p<0.01,{ }^{* * *} p<0.001$.

results raise the possibility that in other animals (e.g., fruit flies, zebrafish), quiescence during sleep under different conditions may be regulated by different mechanisms despite behavioral similarities. Indeed, there are already suggestions that this is the case. For example, mechanisms of regulation of locomotion quiescence in young Drosophila adults are partially distinct from mechanisms in older Drosophila adults (Kayser et al., 2014). 
A

Developmentally Timed Quiescence

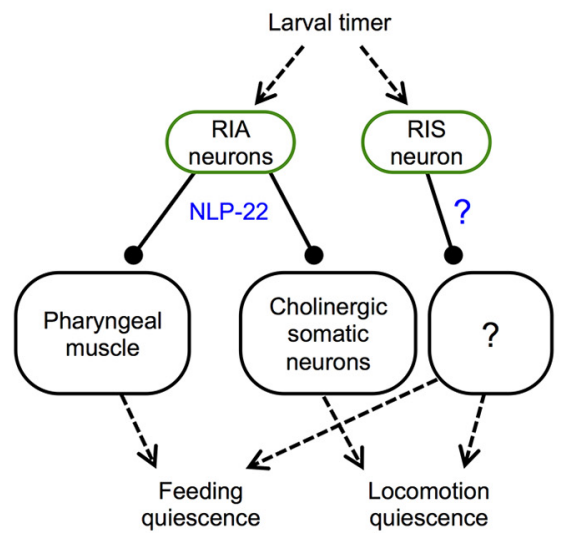

B

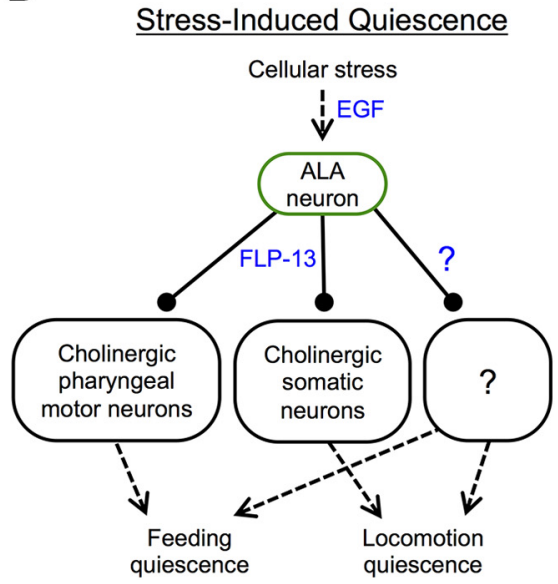

Figure 8. Model for quiescence regulation during SIQ and DTQ. Green ovals represent somatic interneurons and blue text represents molecular mechanisms. Solid lines with arrowheads represent positive regulation and solid lines with balls on the end represent negative regulation. Dotted lines represent conceptual rather than molecular connections. $A$, During DTQ, an unidentified larval timer causes the RIA interneurons to release NLP-22. NLP-22 inhibits feeding by acting directly on pharyngeal muscles and inhibits locomotion via cholinergic neurons. The RIS interneuron also regulates feeding and locomotion quiescence during DTQ. $B$, Cellular stress triggers release of LIN-3/EGF from an unknown source, which then activates the ALA interneuron, causing release of FLP-13 and other neurotransmitter(s). FLP-13 inhibits feeding and locomotion by acting on pharyngeal and somatic (nonpharyngeal) cholinergic neurons, respectively.

\section{Could the effects of neuropeptide overexpression be due to altered temporal dynamics of SIQ?}

In our neuropeptide overexpression experiments, we used heat to induce somatic transcription of the NLP-22 or FLP-13 neuropeptides. However, as demonstrated here and previously, heat exposure can also trigger behavioral quiescence directly via induction of cellular stress (Jones and Candido, 1999; Hill et al., 2014). Therefore, it is possible that the quiescence-inducing effects of neuropeptide overexpression are confounded by SIQ. To minimize this possibility, we used a lower temperature, $33^{\circ} \mathrm{C}$ versus $35^{\circ} \mathrm{C}$, and a later analysis time point, $2-3 \mathrm{~h}$ versus $35-45 \mathrm{~min}$ after heat exposure, to examine quiescence in response to neuropeptide overexpression. Acute feeding quiescence is less severe after $33^{\circ} \mathrm{C}$ exposure than after $35^{\circ} \mathrm{C}$ exposure (Nelson et al., 2014) and the behavioral effects of a 30 min heat shock at $33^{\circ} \mathrm{C}$ dissipate fully by $2 \mathrm{~h}$ after heat exposure (Nelson et al., 2013, 2014). We also repeated the neuropeptide overexpression experiments in ceh-17 mutants, which have defective SIQ (Hill et al., 2014; Nelson et al., 2014), and found no changes in the quiescence observed in response to neuropeptide overexpression. Finally, we found that 35 min after a mild heat shock at $29^{\circ} \mathrm{C}$, worms overexpressing flp- 13 were quiescent while worms overexpressing $n l p-22$ were not. This suggests that the behavioral effects of $n l p-22$ overexpression are not due to an interaction between neuropeptide overexpression and recovery of cellular stress. Because we did observe acute feeding quiescence using the milder $29^{\circ} \mathrm{C}$ exposure in animals carrying the Phsp-16.2::flp-13 transgene, but not in wild-type animals (Nelson et al., 2014), it is possible that overexpression of $f l p-13$ may amplify the acute stress response, affirming the important role of $f l p-13$ in SIQ.

\section{Feeding quiescence during DTQ is due to a change in pharyngeal muscle excitability}

Our genetic, pharmacologic, and optogenetic experiments indicate that pharyngeal muscle is not excitable during DTQ. Even with direct optogenetic stimulation of pharyngeal muscle, no $\mathrm{Ca}^{2+}$ increase was observed during DTQ, suggesting that $\mathrm{Ca}^{2+}$ entry is impaired during this state. Because pharyngeal $\mathrm{Ca}^{2+}$ increase during feeding occurs primarily via the L-type voltage-gated $\mathrm{Ca}^{2+}$ channel EGL-19 (Lee et al., 1997; Shtonda and Avery, 2005), our results suggest that the EGL-19 $\mathrm{Ca}^{2+}$ current is decreased during DTQ. Transcriptional expression of the egl-19 gene is unchanged during DTQ (George-Raizen et al., 2014), so the reduction in the EGL-19 current is likely due to a posttranscriptional change. This change could occur directly, via modulation of EGL-19 protein expression or function, or indirectly, via an increase in inhibitory currents carried by potassium and/or chloride channels. Our data also suggest that NLP-22 inhibits pharyngeal muscle directly during DTQ, although it must act in parallel to other mechanisms because feeding quiescence is not abolished in nlp-22 mutants (Nelson et al., 2013). NLP-22, like other neuropeptides, may act through a G-protein-coupled receptor to inhibit feeding. Alternatively, like certain small peptides such as Drosophila SLEEPLESS (Koh et al., 2008), it may act like a toxin and interact with ion channels directly (Wu et al., 2010; Dean et al., 2011; Wu et al., 2014). The receptor for NLP-22 is unknown.

\section{Why is quiescence during DTQ and SIQ engaged differently?} Although feeding and locomotion quiescence are both characteristics of DTQ, recent data from many investigators support our conclusion that feeding and locomotion are inhibited at different levels. Several mutants have been described with impaired locomotion quiescence throughout DTQ (Raizen et al., 2008; Singh et al., 2011; Belfer et al., 2013; Choi et al., 2013; Nelson et al., 2013; Schwarz and Bringmann, 2013; Turek et al., 2013; Singh et al., 2014) and DTQ locomotion quiescence can be reduced by mechanical stimulation (Raizen et al., 2008; Driver et al., 2013; Nagy et al., 2014). However, mutations that suppress locomotion quiescence do not appear to affect feeding quiescence because no mutant has been described to feed throughout DTQ. It is possible that feeding quiescence during DTQ is essential for viability.

The differing mechanisms for behavioral quiescence during DTQ and SIQ may reflect the relative importance of the different types of quiescence for survival. DTQ is accompanied by a molt (Singh and Sulston, 1978) and occurs at the end of each of the four larval stages, when the worm has not yet reached reproductive maturity. The completion of each molt is essential for survival and reproduction (Frand et al., 2005), so there is strong selection for worms that can molt successfully. The correct replacement of the pharyngeal cuticle appears to be a vital part of DTQ, as defective pharyngeal molting can be lethal (Singh and Sulston, 1978; George-Raizen et al., 2014). By inhibiting feeding at the level of muscle excitability, the worm increases the likelihood that the pharyngeal cuticle will form properly because no stray neural impulses or neuromodulation could trigger muscle contraction that might disrupt cuticular assembly. Interestingly, mutations that severely decrease quiescence during SIQ can also have a small effect on quiescence during DTQ (Van Buskirk and Sternberg, 2007), suggesting that molting may be stressful and weakly stimulate SIQ. 
In contrast to the precise timing of DTQ, the environmental stresses that trigger SIQ can happen at any point in the life of a worm, and no SIQ-associated structural or morphological changes have been identified. Failure to engage proper SIQ is rarely lethal in the first $24 \mathrm{~h}$ after stress (Hill et al., 2014), so pharyngeal contraction during this state may not be as detrimental to survival. By inducing quiescence at the level of the nervous system, the worm retains the ability to use other neuromodulators such as 5-HT to alter feeding during SIQ. This implies that, although quiescence increases the likelihood of survival in response to cellular stressors (Hill et al., 2014), there may be conditions under which feeding during this state is beneficial.

\section{DTQ and SIQ may be functionally conserved and are regulated by evolutionarily conserved signaling pathways}

There is no evidence to suggest that DTQ and SIQ represent evolutionary forms of subtypes of mammalian sleep. However, DTQ and SIQ may serve functions similar to mammalian sleep: DTQ, which occurs in phase with cycling of the C. elegans homolog of the PERIOD gene (Monsalve et al., 2011), has been implicated in synaptic plasticity (Dabbish and Raizen, 2011) and synthetic metabolism (Frand et al., 2005; Driver et al., 2013), whereas SIQ is important for survival after physiological stressors (Hill et al., 2014). Likewise, mammalian sleep has been implicated in synaptic plasticity (Tononi and Cirelli, 2014), anabolic metabolism (Mackiewicz et al., 2007), and stress responses (Toth and Krueger, 1988; Rampin et al., 1991).

The signaling pathways investigated here, as well as other previously identified regulators of DTQ (Raizen et al., 2008; Singh et al., 2011; Belfer et al., 2013; Choi et al., 2013; Driver et al., 2013; Iwanir et al., 2013; Nagy et al., 2013; Nelson et al., 2013; Schwarz and Bringmann, 2013; Turek et al., 2013; Nagy et al., 2014; Singh et al., 2014; Choi et al., 2015) and SIQ (Hill et al., 2014; Nelson et al., 2014), are found in many cell and neuron types and are highly conserved. These pathways have been implicated in sleep regulation in a variety of species (Allada and Siegel, 2008; Zimmerman et al., 2008; Crocker and Sehgal, 2010), but their ubiquitous expression patterns have made identification of specific cellular and circuit functions for these pathways challenging (but see Crocker et al., 2010). By identifying how these genes affect circuits that regulate different sleep-like states, we will gain insight into the mechanisms and functions of sleep across all species.

\section{References}

Akerboom J, Carreras Calderón N, Tian L, Wabnig S, Prigge M, Tolö J, Gordus A, Orger MB, Severi KE, Macklin JJ, Patel R, Pulver SR, Wardill TJ, Fischer E, Schüler C, Chen TW, Sarkisyan KS, Marvin JS, Bargmann CI, Kim DS, et al. (2013) Genetically encoded calcium indicators for multi-color neural activity imaging and combination with optogenetics. Front Mol Neurosci 6:2. Medline

Albertson DG, Thomson JN (1976) The pharynx of Caenorhabditis elegans. Phil Trans Royal Soc Ser B, Biol Sci 275:299-325. CrossRef

Alkema MJ, Hunter-Ensor M, Ringstad N, Horvitz HR (2005) Tyramine functions independently of octopamine in the Caenorhabditis elegans Nervous System. Neuron 46:247-260. CrossRef Medline

Allada R, Siegel JM (2008) Unearthing the phylogenetic roots of sleep. Curr Biol 18:R670-R679. CrossRef Medline

Avery L (1993) The genetics of feeding in Caenorhabditis elegans. Genetics 133:897-917. Medline

Avery L, Horvitz HR (1989) Pharyngeal pumping continues after laser killing of the pharyngeal nervous system of C. elegans. Neuron 3:473-485. CrossRef Medline

Avery L, You YJ (2012) C. elegans feeding. WormBook 1-23. CrossRef Medline

Bastiani CA, Gharib S, Simon MI, Sternberg PW (2003) Caenorhabditis elegans $\mathrm{G}(\mathrm{q})$ alpha regulates egg-laying behavior via a PLCbeta- independent and serotonin-dependent signaling pathway and likely functions both in the nervous system and in muscle. Genetics 165:18051822. Medline

Belfer SJ, Chuang HS, Freedman BL, Yuan J, Norton M, Bau HH, Raizen DM (2013) Caenorhabditis-in-drop array for monitoring C. elegans quiescent behavior. Sleep 36:689-698G. Medline

Brenner S (1974) The genetics of Caenorhabditis elegans. Genetics 77:71-94. Medline

Cassada RC, Russell RL (1975) The dauerlarva, a post-embryonic developmental variant of the nematode Caenorhabditis elegans. Dev Biol 46:326342. CrossRef Medline

Charlie NK, Thomure AM, Schade MA, Miller KG (2006) The Dunce cAMP phosphodiesterase PDE-4 negatively regulates $\mathrm{G}$ alpha(s)-dependent and $\mathrm{G}$ alpha(s)-independent cAMP pools in the Caenorhabditis elegans synaptic signaling network. Genetics 173:111-130. CrossRef Medline

Chen TW, Wardill TJ, Sun Y, Pulver SR, Renninger SL, Baohan A, Schreiter ER, Kerr RA, Orger MB, Jayaraman V, Looger LL, Svoboda K, Kim DS (2013) Ultrasensitive fluorescent proteins for imaging neuronal activity. Nature 499:295-300. CrossRef Medline

Cho JY, Sternberg PW (2014) Multilevel modulation of a sensory motor circuit during C. elegans sleep and arousal. Cell 156:249-260. CrossRef Medline

Choi S, Chatzigeorgiou M, Taylor KP, Schafer WR, Kaplan JM (2013) Analysis of NPR-1 reveals a circuit mechanism for behavioral quiescence in $C$. elegans. Neuron 78:869-880. CrossRef Medline

Choi S, Taylor KP, Chatzigeorgiou M, Hu Z, Schafer WR, Kaplan JM (2015) Sensory neurons arouse C. elegans locomotion via both glutamate and neuropeptide release. PLoS Genet 11:e1005359. CrossRef Medline

Crocker A, Sehgal A (2010) Genetic analysis of sleep. Genes Dev 24:12201235. CrossRef Medline

Crocker A, Shahidullah M, Levitan IB, Sehgal A (2010) Identification of a neural circuit that underlies the effects of octopamine on sleep:wake behavior. Neuron 65:670-681. CrossRef Medline

Dabbish NS, Raizen DM (2011) GABAergic synaptic plasticity during a developmentally regulated sleep-like state in C. elegans. J Neurosci 31: 15932-15943. CrossRef Medline

Davis MW, Somerville D, Lee RYN, Lockery S, Avery L, Fambrough DM (1995) Mutations in the Caenorhabditis elegans Na, K-ATPase alphasubunit gene, eat-6, disrupt excitable cell function. J Neurosci 15:84088418. Medline

Dean T, Xu R, Joiner W, Sehgal A, Hoshi T (2011) Drosophila QVR/SSS modulates the activation and C-type inactivation kinetics of Shaker K+ channels. J Neurosci 31:11387-11395. CrossRef Medline

Doi M, Iwasaki K (2002) Regulation of retrograde signaling at neuromuscular junctions by the novel C2 domain protein AEX-1. Neuron 33:249259. CrossRef Medline

Driver RJ, Lamb AL, Wyner AJ, Raizen DM (2013) DAF-16/FOXO regulates homeostasis of essential sleep-like behavior during larval transitions in C. elegans. Curr Biol 23:501-506. CrossRef Medline

Dybbs M, Ngai J, Kaplan JM (2005) Using microarrays to facilitate positional cloning: identification of tomosyn as an inhibitor of neurosecretion. PLoS Genet 1:6-16. Medline

Edgley ML, Baillie DL, Riddle DL, Rose AM (2006) Genetic balancers. WormBook 1-32. Medline

Frand AR, Russel S, Ruvkun G (2005) Functional genomic analysis of $C$. elegans molting. PLoS Biol 3:e312. CrossRef Medline

George-Raizen JB, Shockley KR, Trojanowski NF, Lamb AL, Raizen DM (2014) Dynamically-expressed prion-like proteins form a cuticle in the pharynx of Caenorhabditis elegans. Biology Open 3:1139-1149. CrossRef Medline

Gordus A, Pokala N, Levy S, Flavell SW, Bargmann CI (2015) Feedback from network states generates variability in a probabilistic olfactory circuit. Cell 161:215-227. CrossRef Medline

Guo F, Yi W, Zhou M, Guo A (2011) Go signaling in mushroom bodies regulates sleep in Drosophila. Sleep 34:273-281. Medline

Hajdu-Cronin YM, Chen WJ, Patikoglou G, Koelle MR, Sternberg PW (1999) Antagonism between G(o)alpha and G(q)alpha in Caenorhabditis elegans: the RGS protein EAT-16 is necessary for $\mathrm{G}(\mathrm{o})$ alpha signaling and regulates G(q)alpha activity. Genes Dev 13:1780-1793. CrossRef Medline

Hawasli AH, Saifee O, Liu C, Nonet ML, Crowder CM (2004) Resistance to volatile anesthetics by mutations enhancing excitatory neurotransmitter 
release in Caenorhabditis elegans. Genetics 168:831-843. CrossRef Medline

He C, Yang Y, Zhang M, Price JL, Zhao Z (2013) Regulation of sleep by neuropeptide Y-like system in Drosophila melanogaster. PLoS One 8:e74237. CrossRef Medline

Hendricks JC, Williams JA, Panckeri K, Kirk D, Tello M, Yin JC, Sehgal A (2001) A non-circadian role for cAMP signaling and CREB activity in Drosophila rest homeostasis. Nat Neurosci 4:1108-1115. CrossRef Medline

Hill AJ, Mansfield R, Lopez JM, Raizen DM, Van Buskirk C (2014) Cellular stress induces a protective sleep-like state in C. elegans. Curr Biol 24: 2399-2405. CrossRef Medline

Hobson RJ, Hapiak VM, Xiao H, Buehrer KL, Komuniecki PR, Komuniecki RW (2006) SER-7, a Caenorhabditis elegans 5-HT7-like receptor, is essential for the 5-HT stimulation of pharyngeal pumping and egg laying. Genetics 172:159-169. Medline

Humphrey JA, Hamming KS, Thacker CM, Scott RL, Sedensky MM, Snutch TP, Morgan PG, Nash HA (2007) A putative cation channel and its novel regulator: cross-species conservation of effects on general anesthesia. Curr Biol 17:624-629. CrossRef Medline

Iwanir S, Tramm N, Nagy S, Wright C, Ish D, Biron D (2013) The microarchitecture of $C$. elegans behavior during lethargus: homeostatic bout dynamics, a typical body posture, and regulation by a central neuron. Sleep 36:385-395. Medline

Jansen G, Thijssen KL, Werner P, van der Horst M, Hazendonk E, Plasterk RH (1999) The complete family of genes encoding G proteins of Caenorhabditis elegans. Nat Genet 21:414-419. CrossRef Medline

Jeon M, Gardner HF, Miller EA, Deshler J, Rougvie AE (1999) Similarity of the C. elegans developmental timing protein LIN-42 to circadian rhythm proteins. Science 286:1141-1146. CrossRef Medline

Joiner WJ, Crocker A, White BH, Sehgal A (2006) Sleep in Drosophila is regulated by adult mushroom bodies. Nature 441:757-760. CrossRef Medline

Jones D, Candido EP (1999) Feeding is inhibited by sublethal concentrations of toxicants and by heat stress in the nematode Caenorhabditis elegans: relationship to the cellular stress response. J Exp Zool 284:147-157. Medline

Kayser MS, Yue Z, Sehgal A (2014) A critical period of sleep for development of courtship circuitry and behavior in Drosophila. Science 344:269274. CrossRef Medline

Kerr R, Lev-Ram V, Baird G, Vincent P, Tsien RY, Schafer WR (2000) Optical imaging of calcium transients in neurons and pharyngeal muscle of C. elegans. Neuron 26:583-594. CrossRef Medline

Klapoetke NC, Murata Y, Kim SS, Pulver SR, Birdsey-Benson A, Cho YK, Morimoto TK, Chuong AS, Carpenter EJ, Tian Z, Wang J, Xie Y, Yan Z, Zhang Y, Chow BY, Surek B, Melkonian M, Jayaraman V, ConstantinePaton M, Wong GK, Boyden ES (2014) Independent optical excitation of distinct neural populations. Nat Methods 11:338-346. CrossRef Medline

Koh K, Joiner WJ, Wu MN, Yue Z, Smith CJ, Sehgal A (2008) Identification of SLEEPLESS, a sleep-promoting factor. Science 321:372-376. CrossRef Medline

Korswagen HC, Park JH, Ohshima Y, Plasterk RH (1997) An activating mutation in a Caenorhabditis elegans Gs protein induces neural degeneration. Genes Dev 11:1493-1503. CrossRef Medline

Lee RY, Lobel L, Hengartner M, Horvitz HR, Avery L (1997) Mutations in the alphal subunit of an L-type voltage-activated $\mathrm{Ca} 2+$ channel cause myotonia in Caenorhabditis elegans. EMBO J 16:6066-6076. CrossRef Medline

Lenz O, Xiong J, Nelson MD, Raizen DM, Williams JA (2015) FMRFamide signaling promotes stress-induced sleep in Drosophila. Brain Behav Immun 47:141-148. CrossRef Medline

Liewald JF, Brauner M, Stephens GJ, Bouhours M, Schultheis C, Zhen M, Gottschalk A (2008) Optogenetic analysis of synaptic function. Nat Methods 5:895-902. CrossRef Medline

Loomis AL, Harvey EN, Hobart G (1937) Cerebral states during sleep, as studied by human brain potentials. J Exp Psychol 21:127-144. CrossRef

Mackiewicz M, Shockley KR, Romer MA, Galante RJ, Zimmerman JE, Naidoo N, Baldwin DA, Jensen ST, Churchill GA, Pack AI (2007) Macromolecule biosynthesis: a key function of sleep. Physiol Genomics 31: 441-457. CrossRef Medline

Mello CC, Kramer JM, Stinchcomb D, Ambros V (1991) Efficient gene transfer in C. elegans: extrachromosomal maintenance and integration of transforming sequences. EMBO J 10:3959-3970. Medline

Mendel JE, Korswagen HC, Liu KS, Hajdu-Cronin YM, Simon MI, Plasterk RH, Sternberg PW (1995) Participation of the protein G(o)alpha in multiple aspects of behavior in C. elegans. Science 267:1652-1655. CrossRef Medline

Miller KG, Alfonso A, Nguyen M, Crowell JA, Johnson CD, Rand JB (1996) A genetic selection for Caenorhabditis elegans synaptic transmission mutants. Proc Natl Acad Sci U S A 93:12593-12598. CrossRef Medline

Miller KG, Emerson MD, Rand JB (1999) G(o)alpha and diacylglycerol kinase negatively regulate the $\mathrm{G}(\mathrm{q})$ alpha pathway in C. elegans. Neuron 24:323-333. CrossRef Medline

Monsalve GC, Van Buskirk C, Frand AR (2011) LIN-42/PERIOD controls cyclical and developmental progression of C. elegans molts. Curr Biol 21:2033-2045. CrossRef Medline

Morgan PG, Sedensky MM, Meneely PM (1990) Multiple sites of action of volatile anesthetics in Caenorhabditis elegans. Proc Natl Acad Sci U S A 87:2965-2969. Medline

Morgan PG, Kayser EB, Sedensky MM (2007) C. elegans and volatile anesthetics. WormBook 1-11. Medline

Nagy S, Wright C, Tramm N, Labello N, Burov S, Biron D (2013) A longitudinal study of Caenorhabditis elegans larvae reveals a novel locomotion switch, regulated by G s signaling. eLife 2:e00782-e00782. Medline

Nagy S, Tramm N, Sanders J, Iwanir S, Shirley IA, Levine E, Biron D (2014) Homeostasis in C. elegans sleep is characterized by two behaviorally and genetically distinct mechanisms. eLife 3:e04380. Medline

Nelson MD, Fitch DH (2011) Overlap extension PCR: an efficient method for transgene construction. Methods Mol Biol 772:459-470. Medline

Nelson MD, Raizen DM (2013) A sleep state during C. elegans development. Curr Opin Neurobiol 23:824-830. CrossRef Medline

Nelson MD, Trojanowski NF, George-Raizen JB, Smith CJ, Yu CC, Fang-Yen C, Raizen DM (2013) The neuropeptide NLP-22 regulates a sleep-like state in Caenorhabditis elegans. Nat Commun 4:2846. Medline

Nelson MD, Lee KH, Churgin MA, Hill AJ, Van Buskirk C, Fang-Yen C, Raizen DM (2014) FMRFamide-like FLP-13 neuropeptides promote quiescence following heat stress in Caenorhabditis elegans. Curr Biol 24: 2406-2410. CrossRef Medline

Nurrish S, Ségalat L, Kaplan JM (1999) Serotonin inhibition of synaptic transmission: $\mathrm{G}(\mathrm{o})$ alpha decreases the abundance of UNC-13 at release sites. Neuron 24:231-242. CrossRef Medline

Parisky KM, Agosto J, Pulver SR, Shang Y, Kuklin E, Hodge JJ, Kang K, Liu X, Garrity PA, Rosbash M, Griffith LC (2008) PDF cells are a GABAresponsive wake-promoting component of the Drosophila sleep circuit. Neuron 60:672-682. CrossRef Medline

Perez-Mansilla B, Nurrish S (2009) A network of G-protein signaling pathways control neuronal activity in C. elegans. Adv Genet 65:145-192. CrossRef Medline

Pujol N, Torregrossa P, Ewbank JJ, Brunet JF (2000) The homeodomain protein CePHOX2/CEH-17 controls antero-posterior axonal growth in C. elegans. Development 127:3361-3371. Medline

Raizen DM, Lee RY, Avery L (1995) Interacting genes required for pharyngeal excitation by motor neuron MC in Caenorhabditis elegans. Genetics 141:1365-1382. Medline

Raizen DM, Zimmerman JE, Maycock MH, Ta UD, You YJ, Sundaram MV, Pack AI (2008) Lethargus is a Caenorhabditis elegans sleep-like state. Nature 451:569-572. CrossRef Medline

Raizen DM, Song BM, Trojanowski NF, You YJ (2012) Methods for measuring pharyngeal behaviors. WormBook 1-13. CrossRef Medline

Rampin C, Cespuglio R, Chastrette N, Jouvet M (1991) Immobilisation stress induces a paradoxical sleep rebound in rat. Neurosci Lett 126:113118. CrossRef Medline

Renn SC, Park JH, Rosbash M, Hall JC, Taghert PH (1999) A pdf neuropeptide gene mutation and ablation of PDF neurons each cause severe abnormalities of behavioral circadian rhythms in Drosophila. Cell 99:791-802. CrossRef Medline

Reynolds NK, Schade MA, Miller KG (2005) Convergent, RIC-8-dependent Galpha signaling pathways in the Caenorhabditis elegans synaptic signaling network. Genetics 169:651-670. CrossRef Medline

Robatzek M, Thomas JH (2000) Calcium/calmodulin-dependent protein kinase II regulates Caenorhabditis elegans locomotion in concert with a $\mathrm{G}(\mathrm{o}) / \mathrm{G}(\mathrm{q})$ signaling network. Genetics 156:1069-1082. Medline

Saifee O, Wei L, Nonet ML (1998) The Caenorhabditis elegans unc-64 locus 
encodes a syntaxin that interacts genetically with synaptobrevin. Mol Biol Cell 9:1235-1252. CrossRef Medline

Saifee O, Metz LB, Nonet ML, Crowder CM (2011) A gain-of-function mutation in adenylate cyclase confers isoflurane resistance in Caenorhabditis elegans. Anesthesiology 115:1162-1171. CrossRef Medline

Schade MA, Reynolds NK, Dollins CM, Miller KG (2005) Mutations that rescue the paralysis of Caenorhabditis elegans ric-8 (synembryn) mutants activate the $\mathrm{G}$ alpha(s) pathway and define a third major branch of the synaptic signaling network. Genetics 169:631-649. CrossRef Medline

Schwarz J, Bringmann H (2013) Reduced sleep-like quiescence in both hyperactive and hypoactive mutants of the galphaq gene egl-30 during lethargus in Caenorhabditis elegans. PLoS One 8:e75853. CrossRef Medline

Ségalat L, Elkes DA, Kaplan JM (1995) Modulation of serotonin-controlled behaviors by G(o)alpha in Caenorhabditis elegans. Science 267:16481651. CrossRef Medline

Shtonda B, Avery L (2005) CCA-1, EGL-19 and EXP-2 currents shape action potentials in the Caenorhabditis elegans pharynx. J Exp Biol 208: 2177-2190. CrossRef Medline

Siegel JM (2005) Clues to the functions of mammalian sleep. Nature 437: 1264-1271. CrossRef Medline

Singh K, Chao MY, Somers GA, Komatsu H, Corkins ME, Larkins-Ford J, Tucey T, Dionne HM, Walsh MB, Beaumont EK, Hart DP, Lockery SR, Hart AC (2011) C. elegans notch signaling regulates adult chemosensory response and larval molting quiescence. Curr Biol 21:825-834. CrossRef Medline

Singh K, Ju JY, Walsh MB, DiIorio MA, Hart AC (2014) Deep conservation of genes required for both Drosophila melanogaster and Caenorhabditis elegans sleep includes a role for dopaminergic signaling. Sleep 37:14391451. Medline

Singh RN, Sulston JE (1978) Some observations on moulting in Caenorhabditis elegans. Nematologica 24:63-71. CrossRef

Song BM, Avery L (2012) Serotonin activates overall feeding by activating two separate neural pathways in Caenorhabditis elegans. J Neurosci 32: 1920-1931. CrossRef Medline

Starich TA, Lee RY, Panzarella C, Avery L, Shaw JE (1996) eat-5 and unc-7 represent a multigene family in Caenorhabditis elegans involved in cell-cell coupling. J Cell Biol 134:537-548. CrossRef Medline

Tabuse Y, Miwa J (1983) A gene involved in action of tumor promoters is identified and mapped in Caenorhabditis elegans. Carcinogenesis 4:783786. CrossRef Medline

Tononi G, Cirelli C (2014) Sleep and the price of plasticity: from synaptic and cellular homeostasis to memory consolidation and integration. Neuron 81:12-34. CrossRef Medline

Toth LA, Krueger JM (1988) Alteration of sleep in rabbits by Staphylococcus aureus infection. Infect Immun 56:1785-1791. Medline

Trent C, Tsuing N, Horvitz HR (1983) Egg-laying defective mutants of the nematode Caenorhabditis elegans. Genetics 104:619-647. Medline

Trojanowski NF and Fang-Yen C (2015) Simultaneous optogenetic stimulation of individual pharyngeal neurons and monitoring of feeding behavior in intact C. elegans. In: C. elegans: methods and applications
(Haspel G, Biron D, eds). Methods Molecular Biology. New York: Springer Publishing. In Press.

Trojanowski NF, Padovan-Merhar O, Raizen DM, Fang-Yen C (2014) Neural and genetic degeneracy underlies Caenorhabditis elegans feeding behavior. J Neurophysiol 112:951-961. CrossRef Medline

Turek M, Lewandrowski I, Bringmann H (2013) An AP2 transcription factor is required for a sleep-active neuron to induce sleep-like quiescence in C. elegans. Curr Biol 23:2215-2223. CrossRef Medline

Van Buskirk C, Sternberg PW (2007) Epidermal growth factor signaling induces behavioral quiescence in Caenorhabditis elegans. Nat Neurosci 10:1300-1307. CrossRef Medline

van der Linden AM, Moorman C, Cuppen E, Korswagen HC, Plasterk RH (2003) Hyperactivation of the G12-mediated signaling pathway in Caenorhabditis elegans induces a developmental growth arrest via protein kinase C. Curr Biol 13:516-521. CrossRef Medline

van Swinderen B, Saifee O, Shebester L, Roberson R, Nonet ML, Crowder CM (1999) A neomorphic syntaxin mutation blocks volatile-anesthetic action in Caenorhabditis elegans. Proc Natl Acad Sci U S A 96:2479-2484. CrossRef Medline

van Swinderen B, Metz LB, Shebester LD, Mendel JE, Sternberg PW, Crowder CM (2001) G(o)alpha regulates volatile anesthetic action in Caenorhabditis elegans. Genetics 158:643-655. Medline

van Swinderen B, Metz LB, Shebester LD, Crowder CM (2002) A Caenorhabditis elegans pheromone antagonizes volatile anesthetic action through a go-coupled pathway. Genetics 161:109-119. Medline

Wang ZW, Saifee O, Nonet ML, Salkoff L (2001) SLO-1 potassium channels control quantal content of neurotransmitter release at the C. elegans neuromuscular junction. Neuron 32:867-881. CrossRef Medline

Wragg RT, Hapiak VM, Miller SB, Harris GP, Gray JM, Komuniecki PR, Komuniecki RW (2007) Tyramine and octopamine independently inhibit serotonin-stimulated aversive behaviors in Caenorhabditis elegans through two novel amine receptors. J Neurosci 27:13402-13412. CrossRef Medline

Woods IG, Schoppik D, Shi VJ, Zimmerman S, Coleman HA, Greenwood J, Soucy ER, Schier AF (2014) Neuropeptidergic signaling partitions arousal behaviors in zebrafish. J Neurosci 34:3142-3160. CrossRef Medline

Wu MN, Joiner WJ, Dean T, Yue Z, Smith CJ, Chen D, Hoshi T, Sehgal A, Koh K (2010) SLEEPLESS, a Ly-6/neurotoxin family member, regulates the levels, localization and activity of Shaker. Nat Neurosci 13:69-75. CrossRef Medline

Wu M, Robinson JE, Joiner WJ (2014) SLEEPLESS is a bifunctional regulator of excitability and cholinergic synaptic transmission. Curr Biol 24: 621-629. CrossRef Medline

Yeh E, Ng S, Zhang M, Bouhours M, Wang Y, Wang M, Hung W, Aoyagi K, Melnik-Martinez K, Li M, Liu F, Schafer WR, Zhen M (2008) A putative cation channel, NCA-1, and a novel protein, UNC-80, transmit neuronal activity in C. elegans. PLoS Biol 6:e55. CrossRef Medline

Zimmerman JE, Naidoo N, Raizen DM, Pack AI (2008) Conservation of sleep: insights from non-mammalian model systems. Trends Neurosci 31:371-376. CrossRef Medline 